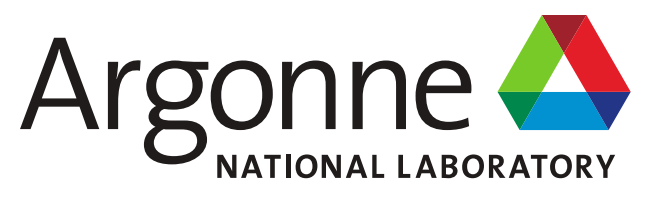

ANL/RTR/TM-18/1 Rev. 2

\title{
Verification and Validation of the STAT7 Code
}

Nuclear Science \& Engineering Division 


\begin{abstract}
About Argonne National Laboratory
Argonne is a U.S. Department of Energy laboratory managed by UChicago Argonne, LLC under contract DE-AC02-06CH11357. The Laboratory's main facility is outside Chicago, at 9700 South Cass Avenue, Argonne, Illinois 60439. For information about Argonne and its pioneering science and technology programs, see www.anl.gov.
\end{abstract}

\title{
DOCUMENT AVAILABILITY
}

Online Access: U.S. Department of Energy (DOE) reports produced after 1991 and a growing number of pre-1991 documents are available free at OSTI.GOV (http://www.osti.gov/), a service of the U.S. Dept. of Energy's Office of Scientific and Technical Information.

\author{
Reports not in digital format may be purchased by the public from the \\ National Technical Information Service (NTIS): \\ U.S. Department of Commerce \\ National Technical Information Service \\ 5301 Shawnee Rd \\ Alexandria, VA 22312 \\ www.ntis.gov \\ Phone: (800) 553-NTIS (6847) or (703) \\ 605-6000 Fax: (703) 605-6900 \\ Email: orders@ntis.gov
}

Reports not in digital format are available to DOE and DOE contractors from the Office of Scientific and Technical Information (OSTI):

U.S. Department of Energy

Office of Scientific and Technical Information

P.O. Box 62

Oak Ridge, TN 37831-0062

www.osti.gov

Phone: (865) 576-8401

Fax: (865) 576-5728

Email: reports@osti.gov

Disclaimer

\section{Disclaimer}

This report was prepared as an account of work sponsored by an agency of the United States Government. Neither the United States Government nor any agency thereof, nor UChicago Argonne, LLC, nor any of their employees or officers, makes any warranty, express or implied, or assumes any legal liability or responsibility for the accuracy, completeness, or usefulness of any information, apparatus, product, or process disclosed, or represents that its use would not infringe privately owned rights. Reference herein to any specific commercial product, process, or service by trade name, trademark, manufacturer, or otherwise, does not necessarily constitute or imply its endorsement, recommendation, or favoring by the United States Government or any agency thereof. The views and opinions of document authors expressed herein do not necessarily state or reflect those of the United States Government or any agency thereof, Argonne National Laboratory, or UChicago Argonne, LLC. 
ANL/RTR/TM-18/1 Rev. 2

\section{Verification and Validation of the STAT7 Code}

prepared by

Son Pham

Nuclear Science \& Engineering Division, Argonne National Laboratory

July 2020 
(This page left intentionally blank) 


\section{Abstract}

This document presents the verification and validation of the STAT7 Version 1.0 code which has been developed to perform the steady-state thermal hydraulic safety calculation of the MIT Research Reactor required upon conversion of the reactor from highly enriched uranium fuel to low- enriched uranium fuel.

The key capabilities of the code including the statistical processing, water property generation, and thermal hydraulic solution are verified independently. While the first two capabilities are checked using statistical tests and NIST data tables, each component of the thermal hydraulic solution is verified using simple geometry test problems. The comparison between results obtained by the code and hand calculations on these problems shows that each of these components work correctly.

Additionally, a comprehensive comparison between STAT7 Version 1.0 and PLTEMP/ANL Version 4.2 calculations for a five-channel test problem is performed for the validation. The good agreement between the obtained results for all thermal hydraulic parameters belonging to the fuel core region is achieved. An issue in bypass flowrate calculation was detected when both fin-friction and bypass flow calculations are involved. This problem can be corrected in a later version of the code. However, it does not affect the application of STAT7 as it has been used to date where the flow distribution in the core region and bypass channel is specified as an input parameter. 


\section{Table of Contents}

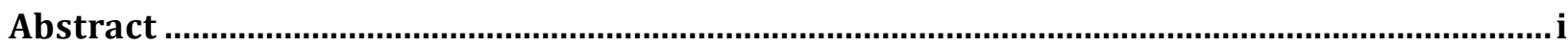

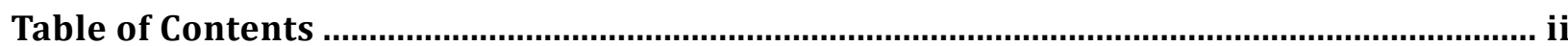

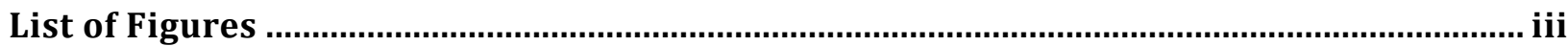

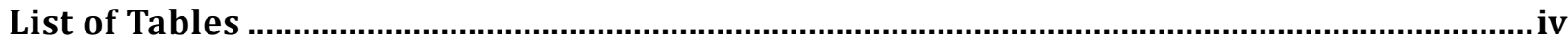

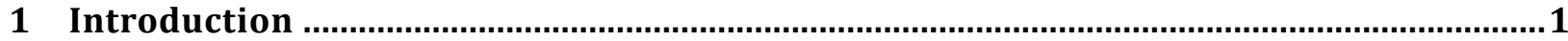

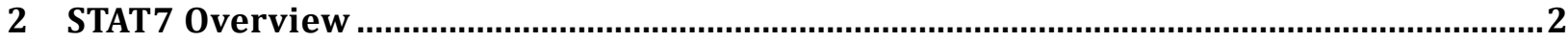

3 Verification Approach and Test Problems.................................................................................

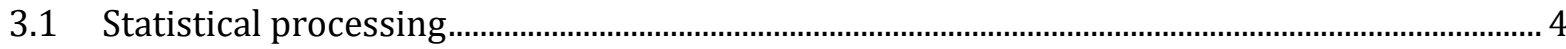

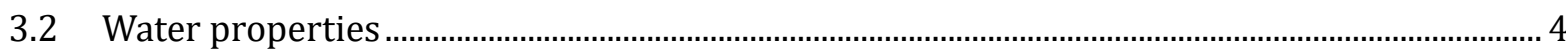

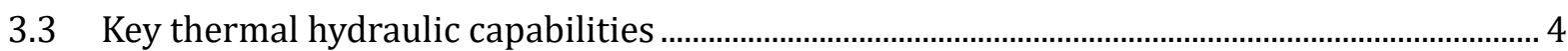

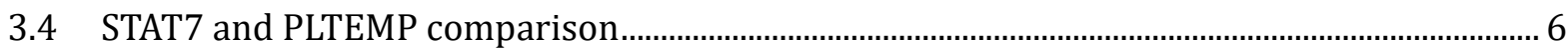

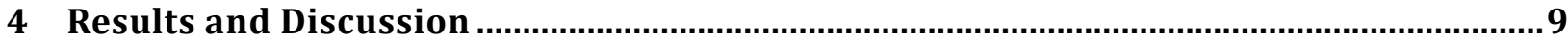

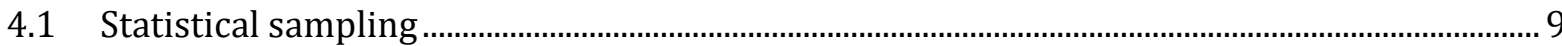

4.2 Coolant properties..........................................................................................................................10

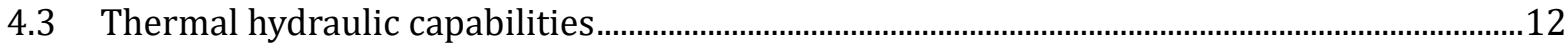

4.3.1 Capability 3A - Basic thermal hydraulic calculation.......................................................13

4.3.2 Capability 3B - Bypass option ...........................................................................................14

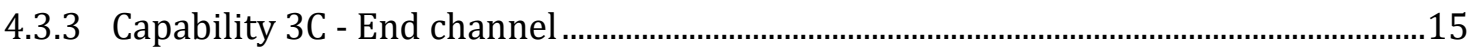

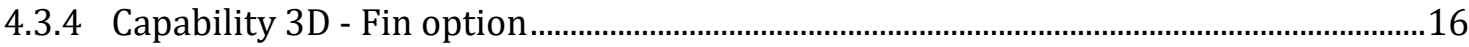

4.3.5 Capability 3E - Viscosity effect on flow rate..........................................................................17

4.3.6 Capability 3F - Power split calculation........................................................................................18

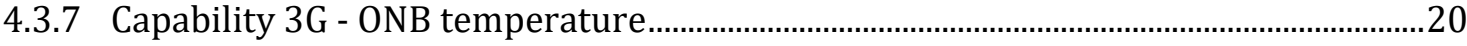

4.4 Comparison between STAT7 and PLTEMP calculations..............................................................20

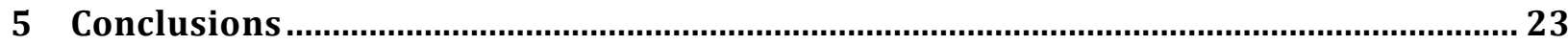

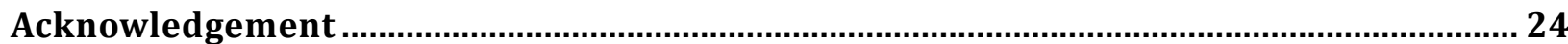

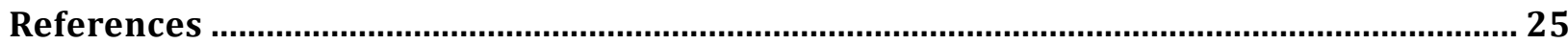

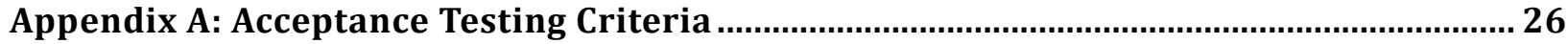

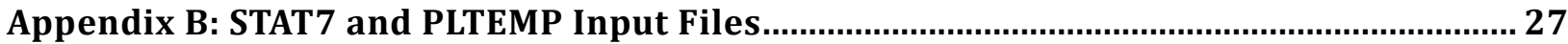

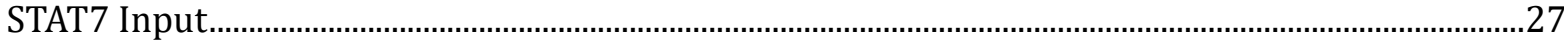

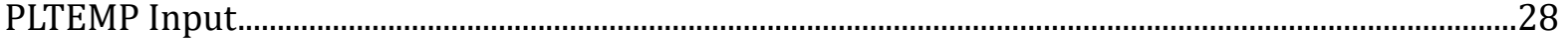




\section{List of Figures}

Figure 1. Main structure of the STAT7 Code.

Figure 2. Cross-section of the test problem geometry used for STAT7 and PLTEMP comparison......... 7

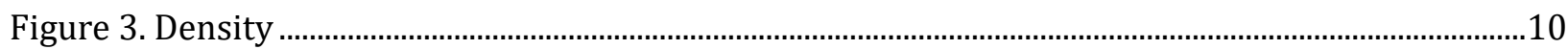

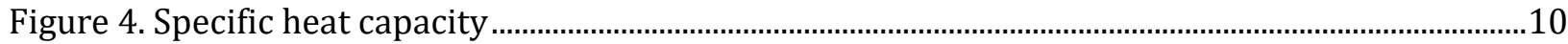

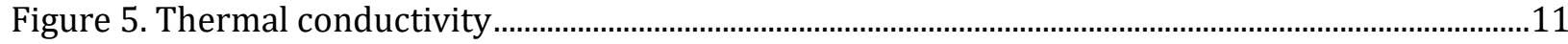

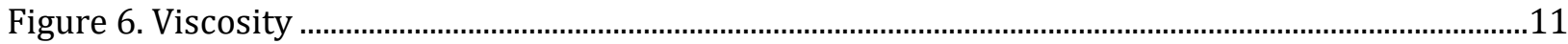

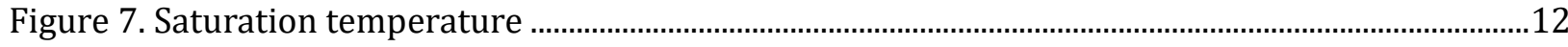

Figure 8. Coolant temperature profiles ..........................................................................................................21

Figure 9. Temperature profiles corresponding to fuel plate \#4 ……............................................................21 


\section{List of Tables}

Table 1. STAT7 code capabilities............................................................................................................... 3

Table 2. Verification approach for thermal hydraulic capabilities ............................................................ 5

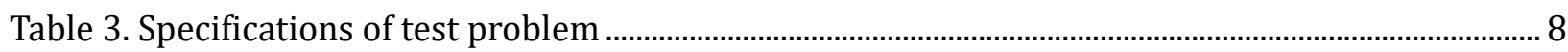

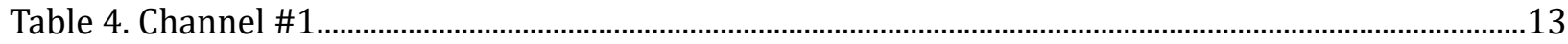

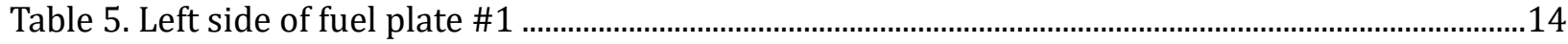

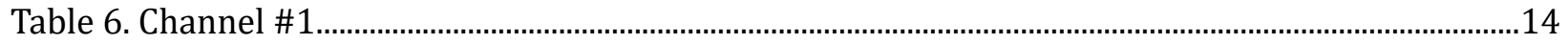

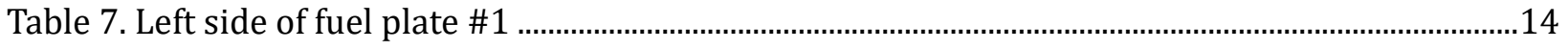

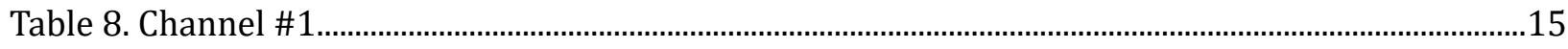

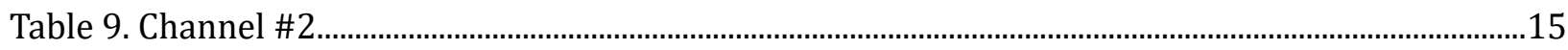

Table 10. Left side of fuel plate \#1 ………….............................................................................................

Table 11. Right side of fuel plate \#1 ……………….................................................................................

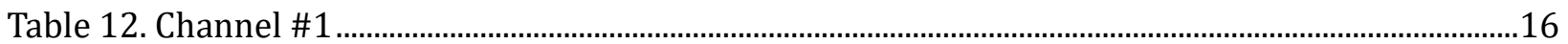

Table 13. Left side of fuel plate \#1 ……........................................................................................................17

Table 14. Channel \#1 ....................................................................................................................................17

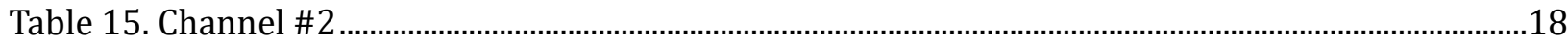

Table 16. Left side of fuel plate \#1 ..................................................................................................................18

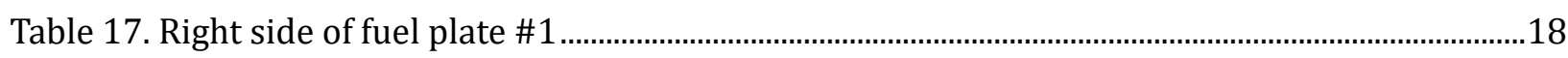

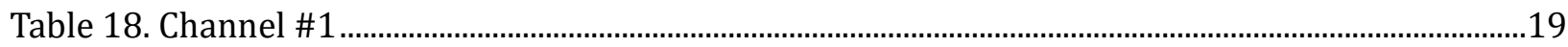

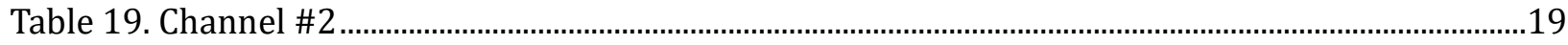

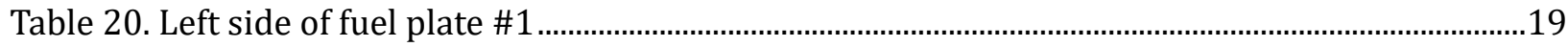

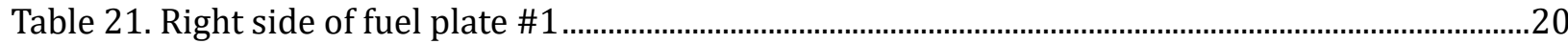

Table 22. Temperature profiles of channel \#1 and left side of plate \#1........................................................20

Table 23. Node-to-node comparison of coolant properties reported by STAT7 and PLTEMP ..............22

Table 24. Comparison of thermal hydraulic data obtained with STAT7 and PLTEMP.............................22

Table 25. Accepted criteria for all test cases.......................................................................................................26 


\section{Introduction}

The STAT7 Version 1.0 code was written to automate many of the steady-state thermal hydraulic safety calculations for the MIT research reactor (MITR) [Ref. 1]. A Monte-Carlo statistical propagation approach is used to treat uncertainties in important parameters in the analysis. In these safety calculations, the limiting safety settings are based on avoiding onset of nucleate boiling (ONB).

This document presents the verification and validation (V\&V) of STAT7 through the following steps:

(1) The statistical capability is evaluated by checking the random number generator embedded in the code. MATLAB is used to rebuild this generator and to test the randomness of the generated numbers.

(2) The fit functions used by the code to generate coolant properties are checked by comparing the obtained data with those calculated by NIST/ASME Steam Formulation for General and Scientific Use [Ref. 2].

(3) The key results of the thermal hydraulic (TH) solution are verified independently by comparison between the code and hand calculations. A simple geometry test problem without the statistical sampling is solved. This test problem is modified into the test cases to consider each of the following thermal hydraulics capabilities: basic thermal hydraulic calculation, bypass flow, end-channel treatment, fin option, effects of viscosity on flow rate, power split, and ONB temperature.

(4) A comprehensive comparison is performed between STAT7 Version 1.0 and PLTEMPANL_4.2_r80_160720 [Ref. 3] calculations using a five-channel test problem with finned fuel plates.

The separation of the thermal hydraulics capabilities in (3) is to avoid the situation in which the errors caused by two or more capabilities compensate to each other, while the comprehensive comparison in (4) is to confirm that all these capabilities can work together correctly.

Following a quick overview of the STAT7 presented in Section 2, the detailed descriptions of these verification approaches and test problems are given in Sections 3. After that, Section 4 discusses calculated results supporting the conclusions that are presented in Section 5.

In addition, Appendix A declares the acceptance testing criteria including acceptance values and tolerances of output parameters that need to be monitored for each test problem. These criteria can be used by the acceptance test to confirm that a newly installed or compiled code version provides similar results that are sufficiently accurate compared to those obtained the version considered in the current V\&V. The inputs for STAT7 and PLTEMP test models used for the code-to-code comparison are also provided in Appendix B. 


\section{STAT7 Overview}

The main structure of STAT7 is presented in Figure 1. Beside the statistical sampling and processing, the remaining important part is the thermal hydraulic solution embedded in the subroutine THYDRL. All of the code's capabilities are briefly described in Table 1.

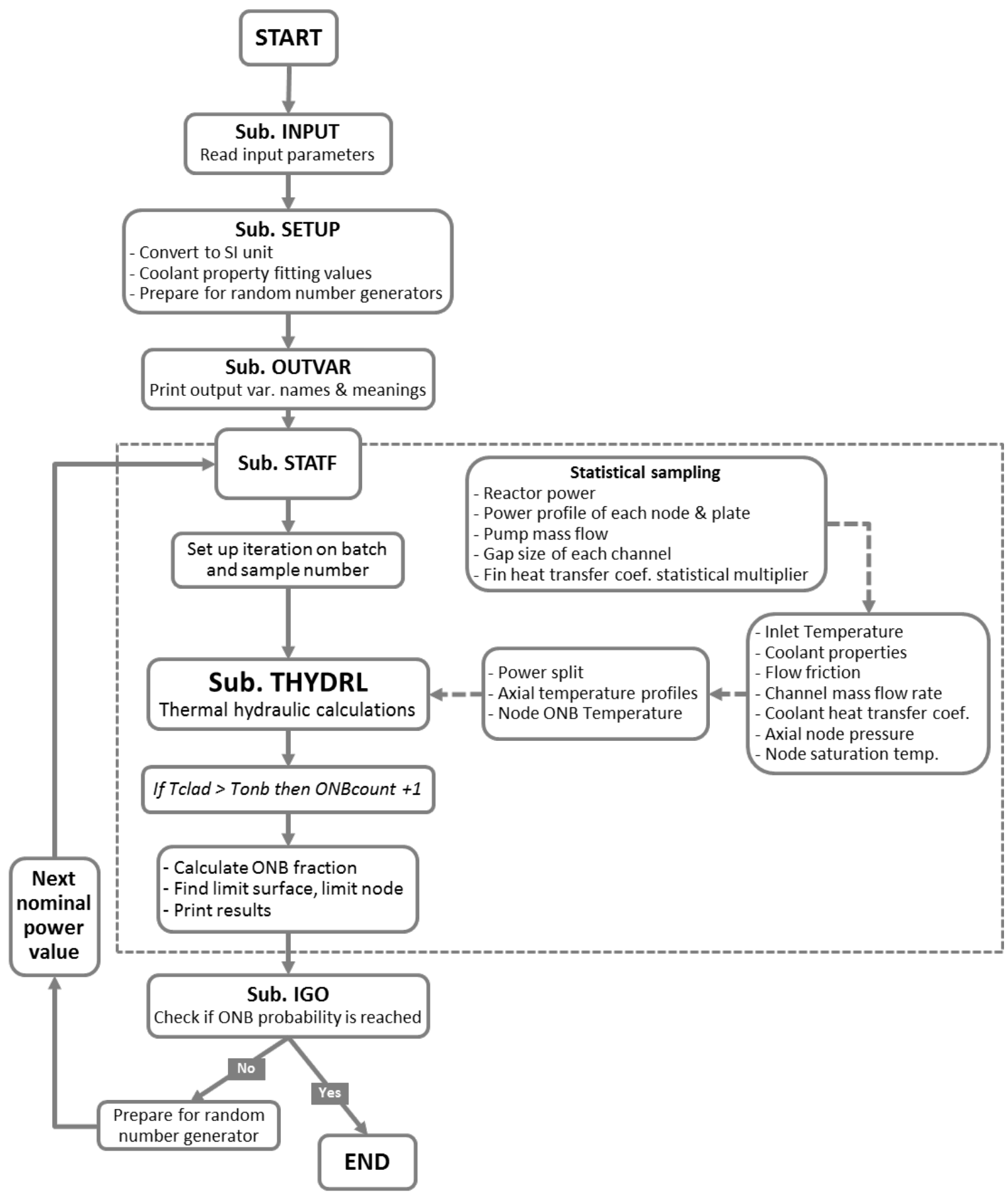

Figure 1. Main structure of the STAT7 Code. 
Table 1. STAT7 code capabilities

\begin{tabular}{|c|l|l|}
\hline No. & \multicolumn{1}{|c|}{ Capabilities } & \multicolumn{1}{c|}{ Description } \\
\hline 1 & Statistical sampling & Generation of random numbers for statistical sampling process \\
\hline 2 & Water property & Generation of water properties using embedded fit functions \\
\hline 3A & Basic TH calculation & Basic TH calculation \\
\hline 3B & Bypass option & TH calculation with the present of bypass channel \\
\hline 3C & End-channel treatment & TH calculation with different boundary conditions of end-channel \\
\hline 3D & Fin option & TH calculation with the existence of fins on fuel cladding surfaces \\
\hline 3E & Viscosity effect & TH calculation considering the effect of viscosity on flowrate \\
\hline 3F & Power split & TH calculation taking the asymmetry power split into account \\
\hline 3G & ONB Temperature & Checking node's surface temperature against the ONB limit \\
\hline
\end{tabular}




\section{Verification Approach and Test Problems}

\subsection{Statistical processing}

The random number generator embedded in the code is checked using two statistical tests including Chi-squared and Runs tests. MATLAB commands are used to rebuild this generator and to check the generated set of numbers against these tests.

\subsection{Water properties}

Verification of the fitted functions used by the code to generate coolant properties including density, specific heat capacity, viscosity, and saturation temperature are performed by comparing the obtained parameters with the data calculated by NIST/ASME Steam Formulation for General and Scientific Uses. The calculation is perform for the ranges of temperature from 10 to $95^{\circ} \mathrm{C}$ and pressure from 0.9 to 1.5 bar which cover the MITR operation flow condition. As will be seen in the Section 4.2, the data predicted by STAT7 agree well with those obtained with the NIST steam formulas. Therefore, for the convenience, hand calculation of thermal hydraulics parameters will use these fit functions to determine coolant properties.

\subsection{Key thermal hydraulic capabilities}

For the verification of the thermal hydraulic solution, both code and hand calculations use the nominal data (without the statistical sampling). Simple geometry test problem of two channels was set up and then modified to form test cases to consider the thermal hydraulics capabilities independently. Several assumptions are applied in each test case to isolate one key capability from others. For example, during the consideration of the fin-option, the effects of viscosity on the channel flow rates are assumed negligible. Accordingly, the code's control options are specified in the input deck to focus on the key capability under considered. The summary of the thermal hydraulic verification approach is presented in Table 2 .

It should be noted that if the equal power split assumption is used in the cases of non-identical channels (3C and 3E), the peak fuel temperature obtained for the left and right sides of the fuel plate will be different from each other. Although this is physically unreasonable, the code and hand calculation still employ the assumption to separate the power split calculation from other capabilities. 
Table 2. Verification approach for thermal hydraulic capabilities

\begin{tabular}{|c|c|c|c|}
\hline Capabilities & $\begin{array}{c}\text { STAT7 Version } 1.0 \\
\text { test model }\end{array}$ & Hand calculation scheme & $\begin{array}{l}\text { Geometry } \\
\text { description }\end{array}$ \\
\hline $\begin{array}{l}\text { 3A. Basic } \\
\text { thermal } \\
\text { hydraulic } \\
\text { calculation }\end{array}$ & $\begin{array}{l}\text { Set up base model: } \\
\text { - } \text { Two identical } \\
\text { channels } \\
\text { - } \text { One fuel plate with } \\
\text { constant power } \\
\text { density } \\
\text { - } \quad \text { Use adiabatic } \\
\text { boundary condition } \\
\text { with non-fuel plates. } \\
\text { - Zero fin height } \\
\text { (unfinned plate) } \\
\text { - Ignore viscosity } \\
\text { effect on flow rate } \\
\text { - No bypass } \\
\text { - Use nominal values }\end{array}$ & 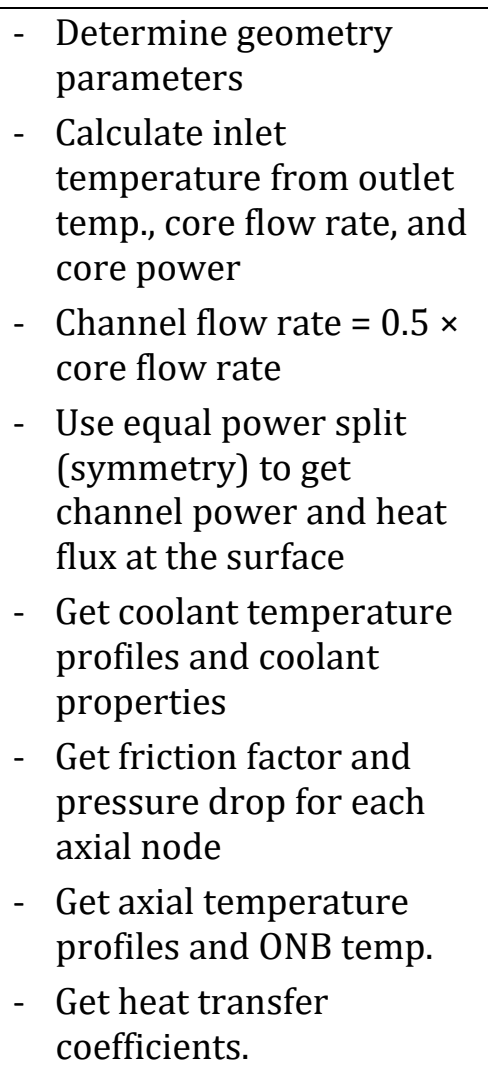 & $\begin{array}{l}\text { - Five axial nodes } \\
\text { - Three stripes } \\
\text { - Upward flow } \\
\text { Cross-section: } \\
\text {. }\end{array}$ \\
\hline $\begin{array}{l}\text { 3B. Bypass } \\
\text { option }\end{array}$ & $\begin{array}{l}\text { Modify the base model: } \\
\text { - } \text { Add bypass flow } \\
\text { with the same } \\
\text { hydraulic diameter } \\
\text { as in the channel } \\
\text { - } \quad \text { Increase pump flow }\end{array}$ & $\begin{array}{l}\text { - Core flow rate }=\text { Core flow } \\
\text { area } \times \text { Total flow rate } / \\
\text { (Core flow area }+ \text { Bypass } \\
\text { flow area) } \\
\text { - } \text { Repeat 3A }\end{array}$ & 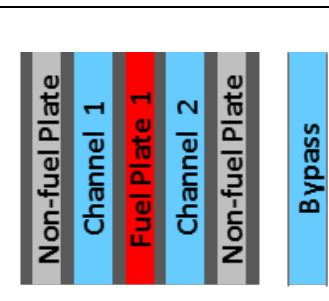 \\
\hline $\begin{array}{l}\text { 3C. End-channel } \\
\text { treatment }\end{array}$ & $\begin{array}{l}\text { Modify the base model: } \\
\text { - } \text { Remove } 3 \text { rd plate by } \\
\text { setting IENDN =0 } \\
\text { - } \quad \text { Use equal power } \\
\text { split (ioptn2=1) }\end{array}$ & $\begin{array}{l}\text { - } \text { Determine geometry } \\
\text { parameters } \\
\text { - } \text { Calculate channel } \\
\text { frictions and channel flow } \\
\text { rates } \\
\text { - } \\
\text { Repeat } 3 \mathrm{~A}\end{array}$ & 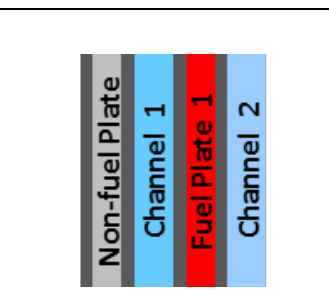 \\
\hline 3D. Fin option & $\begin{array}{l}\text { Modify the base model: } \\
\text { - Add fins }\end{array}$ & $\begin{array}{l}\text { - Determine geometry } \\
\text { parameters with the } \\
\text { present of the fins } \\
\text { - Repeat } 3 \text { A using Carnavos } \\
\text { correlation of heat } \\
\text { transfer at clad surface }\end{array}$ & 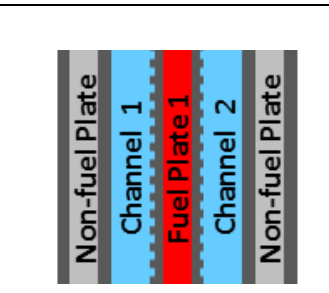 \\
\hline
\end{tabular}




\begin{tabular}{|c|c|c|c|}
\hline Capabilities & $\begin{array}{c}\text { STAT7 Version } 1.0 \\
\text { test model }\end{array}$ & Hand calculation scheme & $\begin{array}{c}\text { Geometry } \\
\text { description }\end{array}$ \\
\hline $\begin{array}{l}\text { 3E. Viscosity } \\
\text { effect on } \\
\text { flow rate }\end{array}$ & $\begin{array}{l}\text { Modify the base model: } \\
\text { - Add one channel } \\
\text { and one fuel plate } \\
\text { - } \text { Remove Oxide \& Zr } \\
\text { layers } \\
\text { - } \text { Use viscosity effect } \\
\text { - Use equal power } \\
\text { split }\end{array}$ & $\begin{array}{l}\text { - Calculate inlet } \\
\text { temperature } \\
\text { - } \text { Two-step iteration to get } \\
\text { outlet temperature, } \\
\text { average temperature, } \\
\text { average viscosity, and } \\
\text { flow rate for each } \\
\text { channel. } \\
\text { - } \text { Repeat 3A }\end{array}$ & 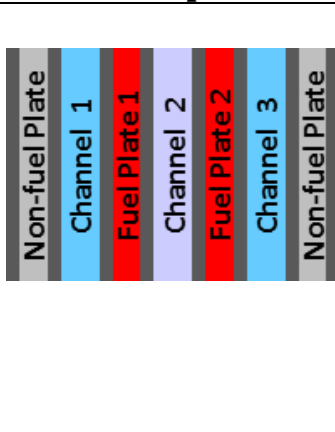 \\
\hline 3F. Power split & $\begin{array}{l}\text { Modify the model of } \\
\text { 3E: } \\
\text { - Use different plate } \\
\text { powers } \\
\text { - Turn on the power } \\
\text { split calculation } \\
\text { - Ignore viscosity } \\
\text { effect on flow rate }\end{array}$ & 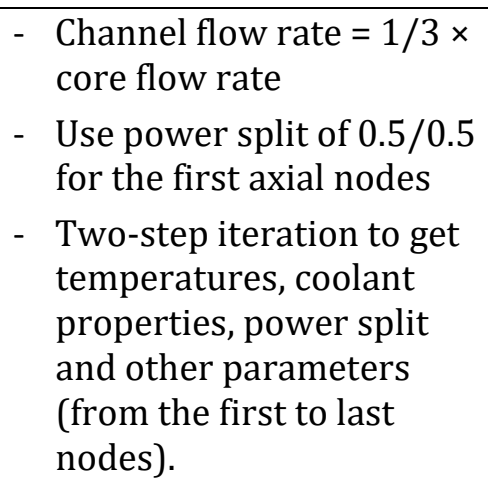 & 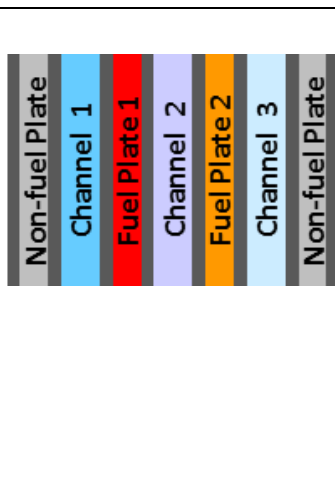 \\
\hline $\begin{array}{l}\text { 3G. ONB } \\
\text { Temperature }\end{array}$ & $\begin{array}{l}\text { Modify the base model: } \\
\text { - Increase core power } \\
\text { until ONB occurs. }\end{array}$ & $\begin{array}{l}\text { - } \text { Repeat 3A } \\
\text { - List out the nodes at } \\
\text { which clad surface } \\
\text { temperature }>\text { ONB } \\
\text { temperature }\end{array}$ & 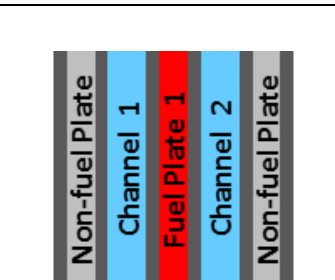 \\
\hline
\end{tabular}

\subsection{STAT7 and PLTEMP comparison}

It should be noted that STAT7 provides two options for the calculations of the flow friction at the end channel with fins at one side: (1) using the Carnavos correlation [Ref. 4] and (2) taking average of the finned and smooth friction factors as in PLTEMP_4.2_r80_160720. Option (2) is used for the comparison between the codes.

A test problem of five channels and four finned fuel plates in which the end-channels have fins at one side is set up for the comparison purpose. To obtain the comparable models of STAT7 and PLTEMP, the following different input specifications of the codes need to be handled during the preparation of input data:

(a) Fin geometry description: STAT7 uses groove depth, groove width, and width of groove tip to specify the series of fins placed continuously on the clad surface. PLTEMP requires the data of fin height (groove depth), fin width (width of groove tip) and total number of fins in channel. Hence, the number of fins on one clad surface needed for PLTEMP is calculated by:

Number of fins $=$ Plate width $/$ (Groove width + Width of groove tip) 
(b) Specified temperature and pressure: STAT7 designed for MITR requires the outlet temperature and pressure to be specified while PLTEMP uses inlet temperature and pressure as the input data. Therefore, the STAT7 model needs to be built and run first. The obtained inlet temperature and pressure is used as the input of PLTEMP model. The comparison between the codes will consider the temperatures of coolant, clad, and fuel as well as pressure, heat flux, and heat transfer coefficients for all axial nodes and channels.

(c) Input flow rate: the total coolant flow rate (including the core flow and bypass flow) can be defined in the input of STAT7 but PLTEMP requires the specification of flow rates in each channel or the total core flowrate if the search option is used. Therefore, the total core flow rates calculated by STAT7 is used for PLTEMP model to allow the code-to-code comparison.

The cross-section and specifications of the test problem are presented in Figure 2 and Table 3, respectively. Both input decks of STAT7 and PLTEMP are given in Appendix B.
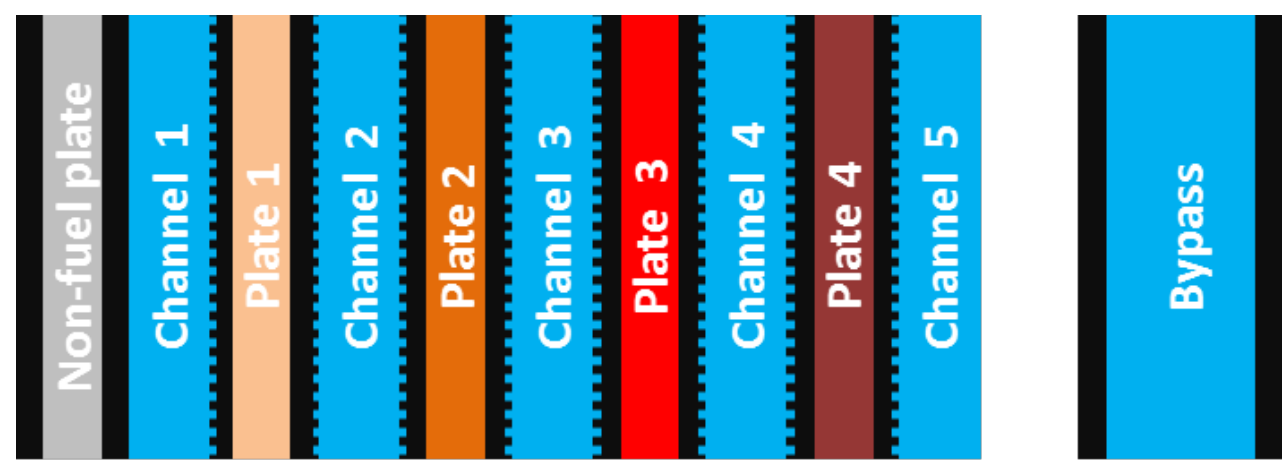

Figure 2. Cross-section of the test problem geometry used for STAT7 and PLTEMP comparison 
Table 3. Specifications of test problem

\begin{tabular}{|c|c|c|c|c|}
\hline Group & \multicolumn{2}{|l|}{ Parameters } & STAT7 & PLTEMP \\
\hline \multirow[t]{8}{*}{ FUEL } & \multicolumn{2}{|l|}{ Number of fuel assemblies } & \multicolumn{2}{|c|}{1} \\
\hline & \multicolumn{2}{|l|}{ Number of fuel plates } & \multicolumn{2}{|c|}{4.0} \\
\hline & \multicolumn{2}{|l|}{ Fuel length, $\mathrm{m}$} & \multicolumn{2}{|c|}{1.0} \\
\hline & \multicolumn{2}{|l|}{ Fuel width, m } & \multicolumn{2}{|c|}{0.4} \\
\hline & \multicolumn{2}{|l|}{ Fuel thickness, m } & \multicolumn{2}{|c|}{0.01} \\
\hline & \multicolumn{2}{|l|}{ Fuel thermal conductivity, $\mathrm{W} / \mathrm{mK}$} & \multicolumn{2}{|c|}{50.0} \\
\hline & \multicolumn{2}{|l|}{ Clad thickness (one side), $\mathrm{m}$} & \multicolumn{2}{|c|}{0.005} \\
\hline & \multicolumn{2}{|l|}{ Clad thermal conductivity, $\mathrm{W} / \mathrm{mK}$} & \multicolumn{2}{|c|}{100.0} \\
\hline \multirow[t]{4}{*}{ FIN } & \multicolumn{2}{|l|}{ Groove depth/Fin height, $\mathrm{m}$} & \multicolumn{2}{|c|}{0.002} \\
\hline & \multicolumn{2}{|l|}{ Width of groove tip/Fin width, m } & \multicolumn{2}{|c|}{0.002} \\
\hline & \multicolumn{2}{|c|}{ Groove width, $\mathrm{m}$} & 0.002 & $*$ \\
\hline & \multicolumn{2}{|l|}{ Number of fins in an internal channel } & & 200 \\
\hline \multirow[t]{12}{*}{ COOLANT } & Number of coolant channels & & & 5 \\
\hline & Left boundary of the first channel & & Non-fu & el plate \\
\hline & Right boundary of the last channe & \#5) & No & late \\
\hline & Coolant channel thickness withou & he present of fins, $\mathrm{m}$ & & 02 \\
\hline & Total flow rate, $\mathrm{kg} / \mathrm{s}$ & & 30.0 & \\
\hline & Core flow rate, $\mathrm{kg} / \mathrm{s}$ & & & $24.577^{* *}$ \\
\hline & Outlet temperature, ${ }^{\circ} \mathrm{C}$ & & 50.0 & \\
\hline & Inlet temperature, ${ }^{\circ} \mathrm{C}$ & & & $34.05^{* *}$ \\
\hline & Outlet pressure, $\mathrm{Pa}$ & & 101325 & \\
\hline & Inlet pressure, $\mathrm{Pa}$ & & & $111300^{* *}$ \\
\hline & Bypass flow area, $\mathrm{m}^{2}$ & & & 05 \\
\hline & Bypass hydraulic diameter, $\mathrm{m}$ & & & 5 \\
\hline POWER & Total power (no deposition in clac & nd coolant), MW & & \\
\hline & & Plate \#1 & & \\
\hline & Ratio of total plate power to core & Plate \#2 & & \\
\hline & average power & Plate \#3 & & 2 \\
\hline & & Plate \#4 & & 6 \\
\hline & & Node $1 /$ Interface 1 & 0.063876 & 0.051998 \\
\hline & & Node 2 / Interface 2 & 0.077787 & 0.065916 \\
\hline & & Node 3/ Interface 3 & 0.089492 & 0.077788 \\
\hline & Axial relative power distribution & Node 4/ Interface 4 & 0.09899 & 0.087616 \\
\hline & obtained from a same power & Node 5/ Interface 5 & 0.106282 & 0.095398 \\
\hline & shape: & Node $6 /$ Interface 6 & 0.111368 & 0.101135 \\
\hline & - STAT7 uses node centers & Node $7 /$ Interface 7 & 0.114248 & 0.104827 \\
\hline & - PLTEMP uses node interfaces & Node $8 /$ Interface 8 & 0.114921 & 0.106474 \\
\hline & & Node $9 /$ Interface 9 & 0.113388 & 0.106075 \\
\hline & & Node $10 /$ Interface 10 & 0.109648 & 0.103631 \\
\hline & & Interface 11 & & 0.099142 \\
\hline
\end{tabular}

(*) Grayed cell indicates a value that is not required by the input deck.

${ }^{(*)}$ The value obtained by the STAT7 calculation that is used for PLTEMP model. 


\section{Results and Discussion}

\subsection{Statistical sampling}

Using MATLAB commands, the random number generator embedded in the STAT7 is rebuilt to generate a set of 200000 numbers. The MATLAB files developed to perform this task are located in the code repository for STAT7 under the verification-related directory. Two statistical tests including Chi-squared test and Runs test [Ref. 5] are considered.

(a) Chi-squared test for distribution

The generated numbers are grouped into 20 bins (degree of freedom is 19). Using the Chi-squared table, the critical values of two-tailed test and a 95\% level of confidence are 8.85 and 32.91. The obtained value of $\chi^{2}$ is

$$
\chi^{2}(19, N=200000)=19.62, p<0.05, \text { two-tailed }
$$

Thus, this test indicates that the generated set of numbers has a uniform distribution.

(b) Runs test for randomness

By coding the numbers above the median as positive and numbers below the median as negative, a run can be defined as a series of consecutive positive or negative values. The number of runs, $r$, detected for the generated set of numbers is:

$$
r=99956
$$

With $n_{1}$ and $n_{2}$ are the number of positive and negative values in the series, respectively, the mean, $\mu_{r}$, and standard deviation, $\sigma_{r}$ of the runs are

$$
\begin{gathered}
\mu_{r}=\frac{2 n_{1} n_{2}}{n_{1}+n_{2}}+1=100000 \\
\sigma_{r}=\frac{2 n_{1} n_{2}\left(2 n_{1} n_{2}-n_{1}-n_{2}\right)}{\left(n_{1}+n_{2}\right)^{2}\left(n_{1}+n_{2}-1\right)}=223.6
\end{gathered}
$$

The test statistic, $\mathrm{z}$, is calculated by

$$
z=\frac{r-\mu_{r}}{\sigma_{r}}=-0.201
$$

Comparing to the critical values corresponding to $95 \%$ level of confidence $-1.96<z<1.96$, the test statistic is within this range, and therefore, it is concluded that the numbers are generated randomly. 


\subsection{Coolant properties}

Comparisons between coolant density, specific heat capacity, thermal conductivity, and viscosity obtained using the fit functions embedded in the code and NIST steam formulas at different pressures are presented in Figures 3 to 6 , respectively. The legends also indicate the maximum relative difference between data calculated by these two methods. Figure 7 presents the comparison of saturation temperatures at different pressures.

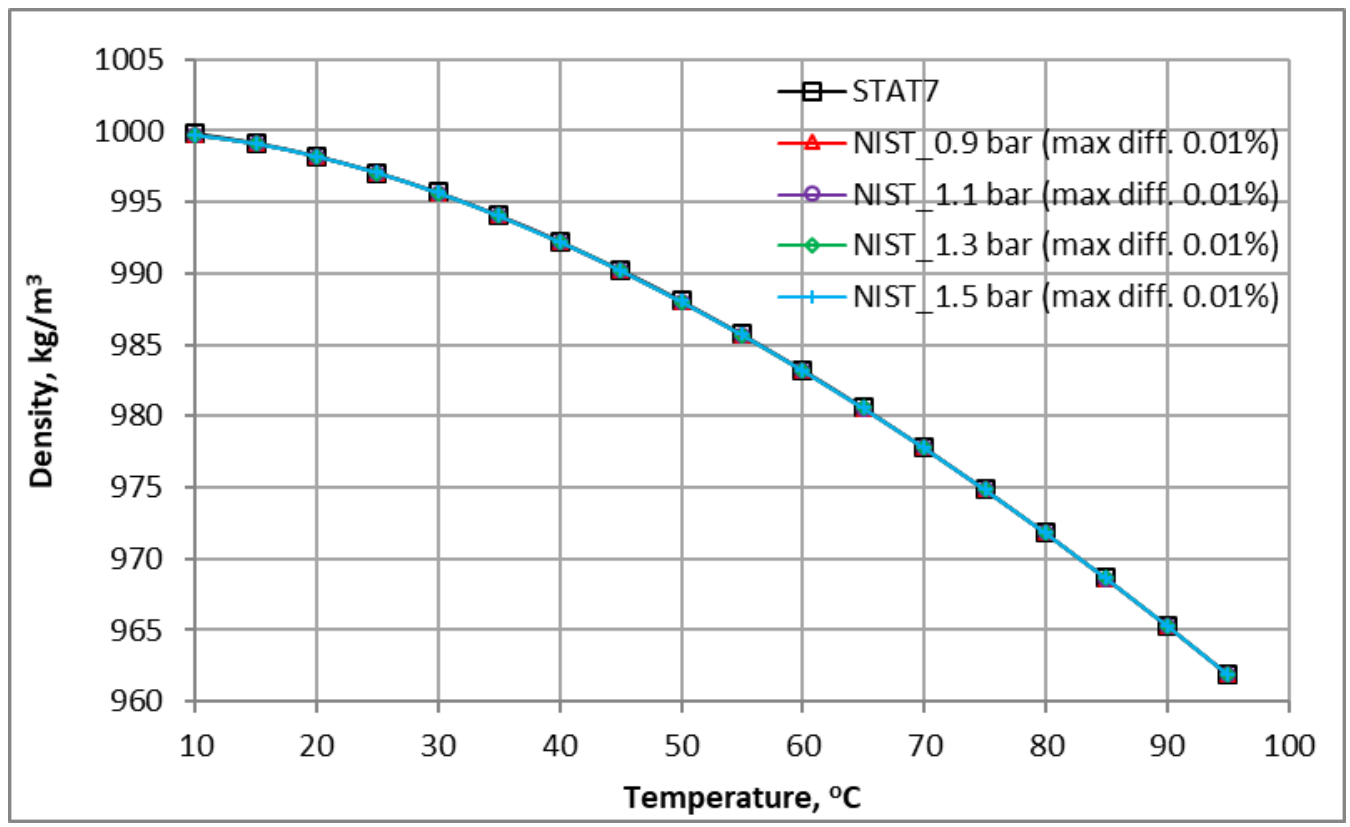

Figure 3. Density

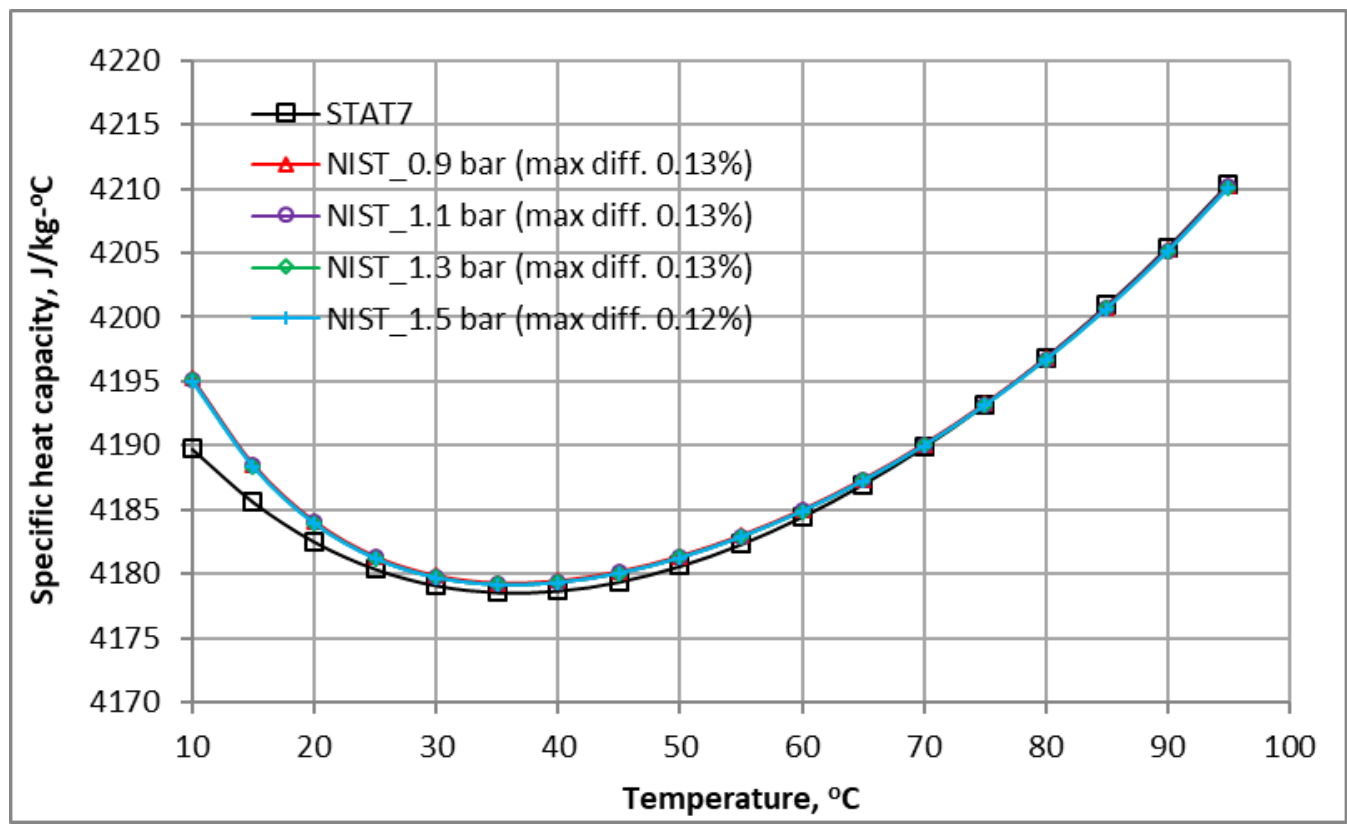

Figure 4. Specific heat capacity 


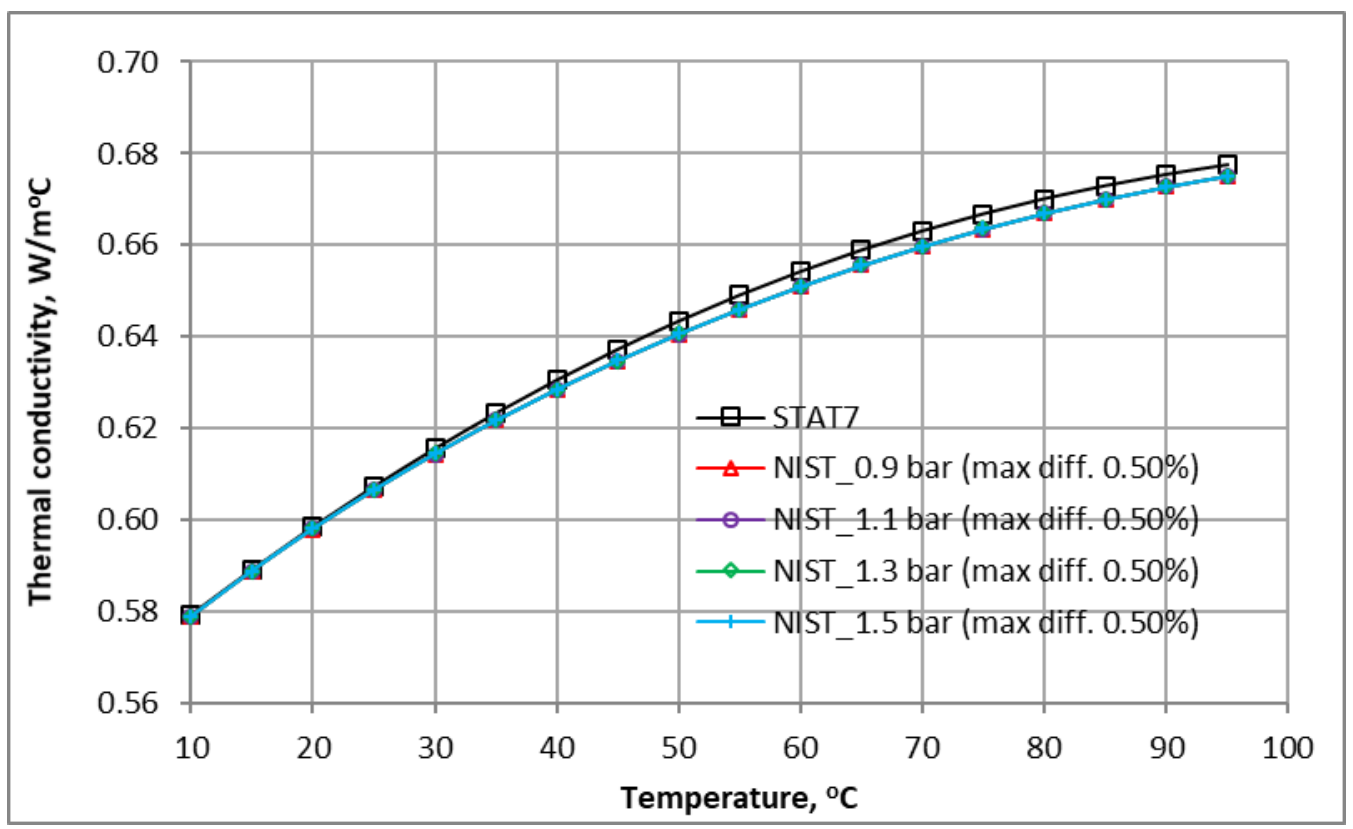

Figure 5. Thermal conductivity

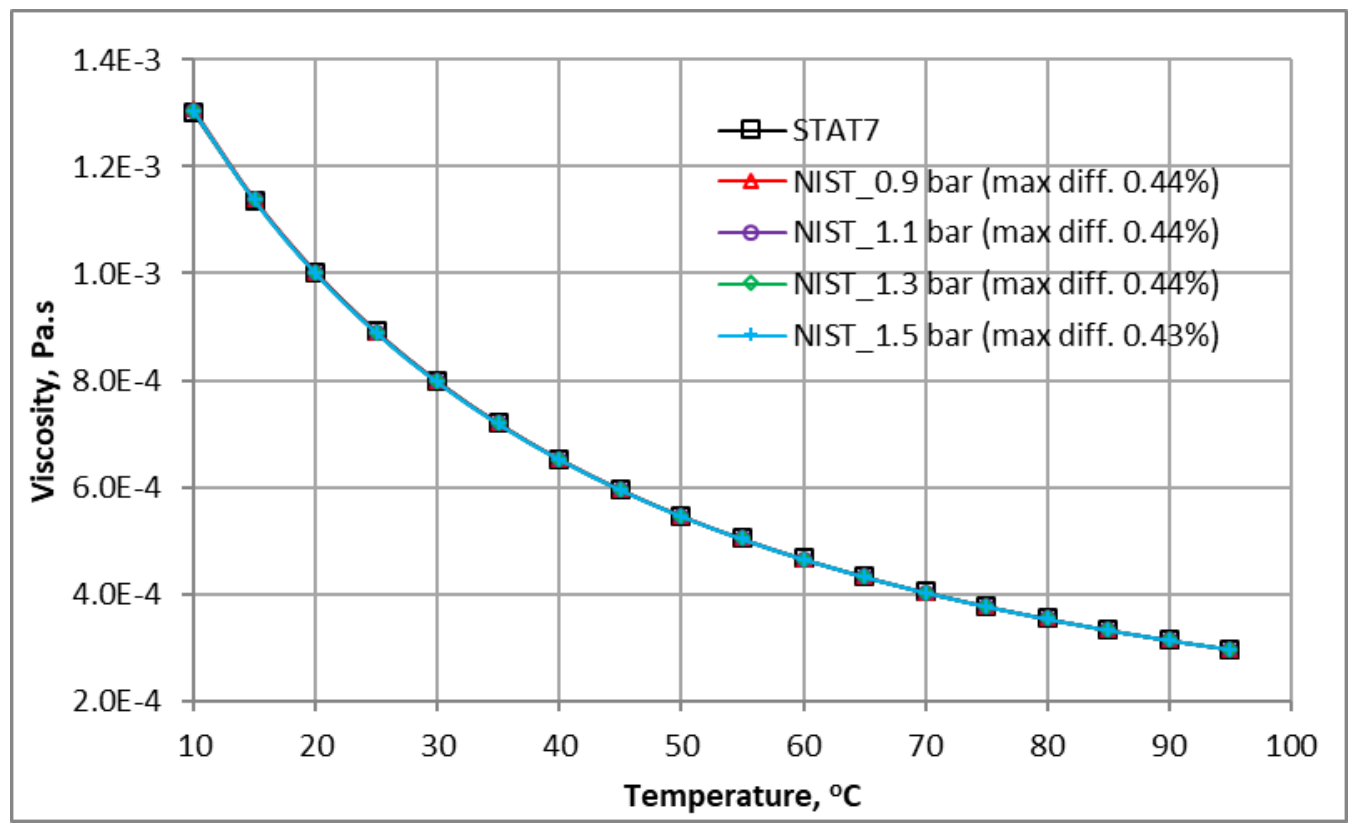

Figure 6. Viscosity 


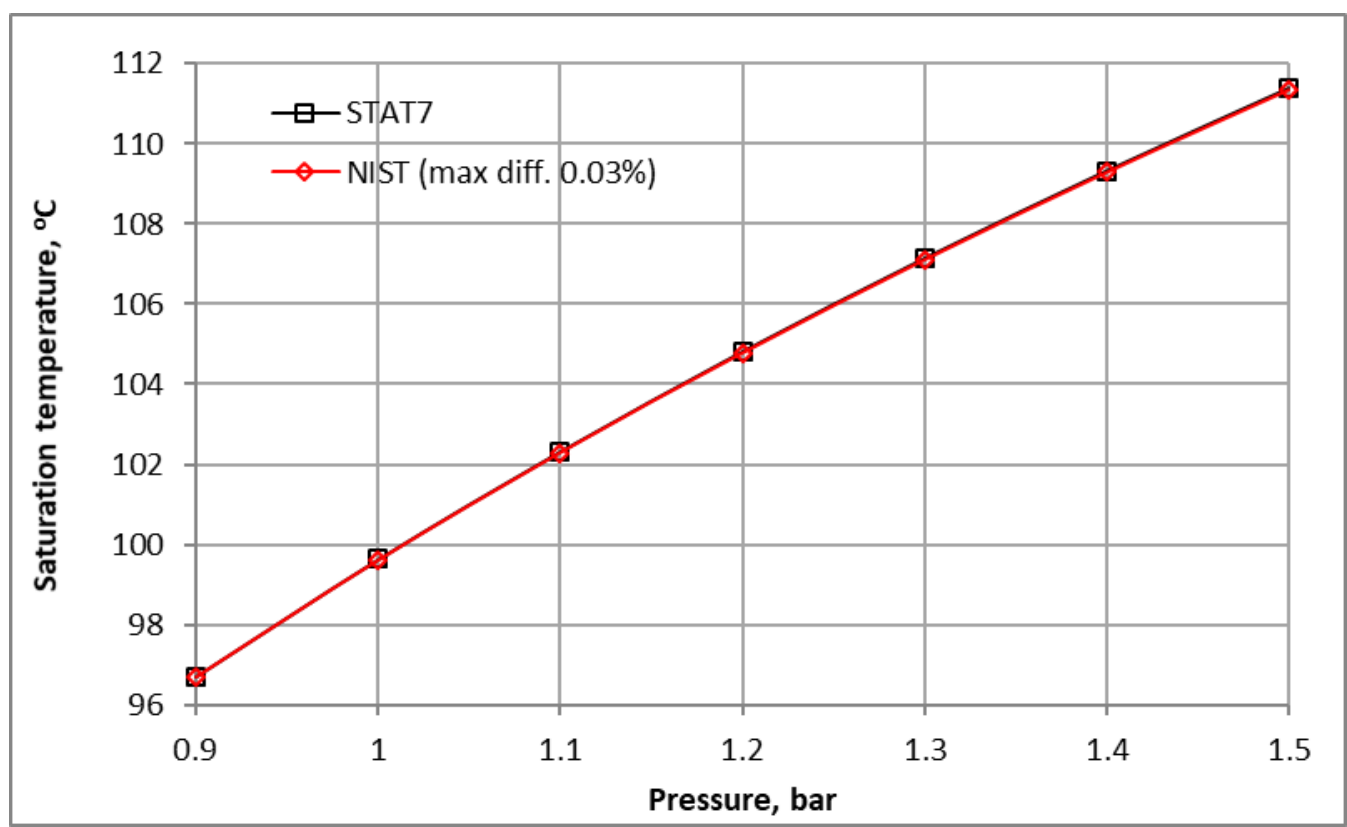

Figure 7. Saturation temperature

It can be seen that all the generated coolant properties for the working flow conditions of the MITR agree well with the values presented on NIST tables. The relative differences less than $0.5 \%$ for all parameters, confirm that the fit functions embedded in the code can predict the properties sufficiently accurately for the expected application ranges of temperature and pressure at MITR.

Based on these results, it is reasonable for the hand calculation subsequently described to employ these fit functions to get the necessary coolant properties.

\subsection{Thermal hydraulic capabilities}

This section presents the comparison between the data obtained by STAT7 and hand calculations for all test cases described in Table 2 . The output variables are as the following:

$\begin{array}{ll}\text { jz } & \text { Axial node } \\ \text { tcoola } & \text { Node averaged coolant temperature, }{ }^{\circ} \mathrm{C} \\ \text { tsata } & \text { Saturation temperature, }{ }^{\circ} \mathrm{C} \\ \text { reya } & \text { Reynolds number } \\ \text { vsca } & \text { Viscosity, Pa*s } \\ \text { rhocla } & \text { Coolant density, } \mathrm{kg} / \mathrm{m}^{3} \\ \text { pcoola } & \text { Pressure, Pa } \\ \text { cpa } & \text { Specific heat capacity, } / \mathrm{kg}^{\circ} \mathrm{C} \\ \text { acc } & \text { Channel coolant flow area, } \mathrm{cm}^{2} \\ \text { dh } & \text { Channel hydraulic diameter, cm } \\ \text { whs } & \text { Channel mass flowrate, } \mathrm{kg} / \mathrm{s} \\ \text { Tsurf } & \text { Clad surface temperature, }{ }^{\circ} \mathrm{C} \\ \text { Tox-cd } & \text { Oxide-clad interface temperature, }{ }^{\circ} \mathrm{C} \\ \text { Tcd-zr } & \text { Clad-Zr interface temperature, }{ }^{\circ} \mathrm{C}\end{array}$


Tzr-f $\quad$ Zr-fuel interface temperature, ${ }^{\circ} \mathrm{C}$

Tfmax $\quad$ Peak fuel temperature, ${ }^{\circ} \mathrm{C}$

Tcd-f Clad-fuel interface temperature (when oxide and $\mathrm{Zr}$ layers have been removed), ${ }^{\circ} \mathrm{C}$

xkcp Film thermal conductivity, $\mathrm{W} /\left(\mathrm{m}_{-}^{\circ} \mathrm{C}\right)$

prp4p $\quad \operatorname{Pr}^{0.4}$ (used by heat transfer correlations)

hcool Film heat transfer coefficient, $\mathrm{W} /\left(\mathrm{m}^{2}{ }_{-}^{\circ} \mathrm{C}\right)$

qc Surface heat flux, $\mathrm{W} / \mathrm{cm}^{2}$

fp Power split (= heat flux at one side / sum of heat fluxes at both sides)

The input and output files of these test cases as well as a Microsoft Excel spreadsheet handling the hand calculation and data comparison are placed in the code repository for STAT7 under the verification-related directory.

The comparison between code and hand calculation in the symmetric two-channel cases $(3 \mathrm{~A}, 3 \mathrm{~B}$, and 3D) evaluate the thermal hydraulic parameters of channel \# 1 and the left side of the fuel plate \#1. For the remaining cases, the comparison includes the channels \#1 and \#2 as well as both sides of the fuel plate \#1. In the following tables, the hand calculation data are present in normal text, while the code results use bold format. Note that the first nonfuel plate of the model is named as Plate \# 1 in the output file and therefore, a fuel plate \#n in Figure 1 or Figure 2 corresponds to the plate \#(n+1) of the output. In addition, the output variables mentioned above are printed out in the output file with numbers 1 and 2 to indicate the left and right sides of the plate.

\subsubsection{Capability 3A - Basic thermal hydraulic calculation}

The obtained thermal hydraulic data of channel \#1 and the left side of fuel plate \#1 of this test case are presented in Table 4 and Table 5. The maximum relative difference between code and hand calculations of all parameters in this test case is $0.09 \%$.

Table 4. Channel \#1

\begin{tabular}{|c|c|c|c|c|c|c|c|}
\hline jZ & tcoola & tsata & reya & vsca & rhocol & pcool & $\mathrm{C}_{1}$ \\
\hline \multirow{2}{*}{1} & 47.31 & .79 & & $5.722 \mathrm{E}-4$ & 989.41 & 120907 & \\
\hline & 47.31 & & 0 & $5.722 \mathrm{E}-4$ & 989.40 & 120900 & \\
\hline \multirow{2}{*}{2} & 47.91 & & & $5.664 \mathrm{E}-4$ & 989.15 & 118923 & \\
\hline & 47.91 & & & $5.664 \mathrm{E}-4$ & 989.20 & 118900 & \\
\hline \multirow{2}{*}{3} & 48.50 & & & $5.606 \mathrm{E}-4$ & 988.89 & 116938 & \\
\hline & 48.50 & & & $5.606 \mathrm{E}-4$ & 988.90 & 116900 & \\
\hline \multirow{2}{*}{4} & 49.10 & & 9 & $5.549 \mathrm{E}-4$ & 988.63 & 114955 & \\
\hline & 49.10 & & 720 & $5.549 \mathrm{E}-4$ & 988.60 & & \\
\hline 5 & 49.70 & & 7281 & $5.493 \mathrm{E}-4$ & & & \\
\hline 5 & 49.70 & 102.83 & 72820.0 & 5.493 & 98 & 113000 & 4181.00 \\
\hline & & & & & & & \\
\hline & & & & & & & 2.000 \\
\hline
\end{tabular}


Table 5. Left side of fuel plate \# 1

\begin{tabular}{|l|c|c|c|c|c|c|c|c|c|}
\hline jz & Tsurf & Tox-cd & Tcd-zr & Tzr-f & Tfmax & xkcp & prp4p & hcool & qc \\
\hline \multirow{2}{*}{1} & 100.70 & 125.70 & 138.20 & 163.20 & 175.70 & 0.6401 & 1.6943 & 4682.8 & 25.00 \\
\cline { 2 - 10 } & $\mathbf{1 0 0 . 7 4}$ & $\mathbf{1 2 5 . 7 4}$ & $\mathbf{1 3 8 . 2 4}$ & $\mathbf{1 6 3 . 2 4}$ & $\mathbf{1 7 5 . 7 4}$ & $\mathbf{0 . 6 4 0 1}$ & $\mathbf{1 . 6 9 3 0}$ & $\mathbf{4 6 7 9 . 0}$ & $\mathbf{2 5 . 0 0}$ \\
\hline \multirow{2}{*}{2} & 101.04 & 126.04 & 138.54 & 163.54 & 176.04 & 0.6408 & 1.6866 & 4705.5 & 25.00 \\
\cline { 2 - 10 } & $\mathbf{1 0 1 . 0 8}$ & $\mathbf{1 2 6 . 0 8}$ & $\mathbf{1 3 8 . 5 8}$ & $\mathbf{1 6 3 . 5 8}$ & $\mathbf{1 7 6 . 0 8}$ & $\mathbf{0 . 6 4 0 8}$ & $\mathbf{1 . 6 8 5 0}$ & $\mathbf{4 7 0 2 . 0}$ & $\mathbf{2 5 . 0 0}$ \\
\hline \multirow{2}{*}{3} & 101.38 & 126.38 & 138.88 & 163.88 & 176.38 & 0.6416 & 1.6789 & 4728.1 & 25.00 \\
\cline { 2 - 10 } & $\mathbf{1 0 1 . 4 2}$ & $\mathbf{1 2 6 . 4 2}$ & $\mathbf{1 3 8 . 9 2}$ & $\mathbf{1 6 3 . 9 2}$ & $\mathbf{1 7 6 . 4 2}$ & $\mathbf{0 . 6 4 1 6}$ & $\mathbf{1 . 6 7 8 0}$ & $\mathbf{4 7 2 4 . 0}$ & $\mathbf{2 5 . 0 0}$ \\
\hline \multirow{2}{*}{4} & 101.73 & 126.73 & 139.23 & 164.23 & 176.73 & 0.6423 & 1.6714 & 4750.7 & 25.00 \\
\cline { 2 - 10 } & $\mathbf{1 0 1 . 7 7}$ & $\mathbf{1 2 6 . 7 7}$ & $\mathbf{1 3 9 . 2 7}$ & $\mathbf{1 6 4 . 2 7}$ & $\mathbf{1 7 6 . 7 7}$ & $\mathbf{0 . 6 4 2 3}$ & $\mathbf{1 . 6 7 0 0}$ & $\mathbf{4 7 4 7 . 0}$ & $\mathbf{2 5 . 0 0}$ \\
\hline \multirow{2}{*}{5} & 102.08 & 127.08 & 139.58 & 164.58 & 177.08 & 0.6430 & 1.6639 & 4773.2 & 25.00 \\
\cline { 2 - 9 } & $\mathbf{1 0 2 . 1 2}$ & $\mathbf{1 2 7 . 1 2}$ & $\mathbf{1 3 9 . 6 2}$ & $\mathbf{1 6 4 . 6 2}$ & $\mathbf{1 7 7 . 1 2}$ & $\mathbf{0 . 6 4 3 0}$ & $\mathbf{1 . 6 6 3 0}$ & $\mathbf{4 7 6 9 . 0}$ & $\mathbf{2 5 . 0 0}$ \\
\hline
\end{tabular}

\subsubsection{Capability 3B - Bypass option}

The maximum relative difference between code and hand calculations of all parameters in this test case is $0.09 \%$. This includes the bypass flowrates obtained with the code and hand calculations of 21.58 and $21.60 \mathrm{~kg} / \mathrm{s}$, respectively.

Table 6. Channel \#1

\begin{tabular}{|c|c|c|c|c|c|c|c|}
\hline jz & tcoola & tsata & reya & vsca & rhocol & pcool & сра \\
\hline \multirow[b]{2}{*}{1} & 49.25 & 104.81 & 36720.2 & $5.535 \mathrm{E}-4$ & 988.54 & 120996 & \\
\hline & 49.25 & 104.81 & & $5.535 \mathrm{E}-4$ & 988.50 & 121000 & \\
\hline \multirow{2}{*}{2} & 49.75 & 104.33 & & $5.489 \mathrm{E}-4$ & 988.32 & 118993 & \\
\hline & 49.75 & 104.33 & & $5.489 \mathrm{E}-4$ & 988.30 & 119000 & \\
\hline \multirow{2}{*}{3} & 50.25 & 103.83 & & $5.443 \mathrm{E}-4$ & 988.09 & 116991 & \\
\hline & 50.25 & 103.83 & & $5.443 \mathrm{E}-4$ & 988.10 & 117000 & \\
\hline \multirow{2}{*}{4} & 50.75 & 103 & 889 & $5.398 \mathrm{E}-4$ & & & \\
\hline & 50. & & 389 & 5.3 & & & \\
\hline & 51.25 & 102. & 8966 & 5.35 & 987.64 & 112 & \\
\hline 5 & 51.25 & 102.83 & 89660.0 & 5.35 & 98 & 113000 & 4181.00 \\
\hline & & & & & & & 2.400 \\
\hline & & & & & & & 2.400 \\
\hline
\end{tabular}

Table 7. Left side of fuel plate \#1

\begin{tabular}{|l|c|c|c|c|c|c|c|c|c|}
\hline jz & Tsurf & Tox-cd & Tcd-zr & Tzr-f & Tfmax & xkcp & prp4p & hcool & qc \\
\hline \multirow{2}{*}{1} & 94.68 & 119.68 & 132.18 & 157.18 & 169.68 & 0.6425 & 1.6695 & 5503.2 & 25.00 \\
\cline { 2 - 10 } & $\mathbf{9 4 . 7 2}$ & $\mathbf{1 1 9 . 7 2}$ & $\mathbf{1 3 2 . 2 2}$ & $\mathbf{1 5 7 . 2 2}$ & $\mathbf{1 6 9 . 7 2}$ & $\mathbf{0 . 6 4 2 5}$ & $\mathbf{1 . 6 6 8 0}$ & $\mathbf{5 4 9 9 . 0}$ & $\mathbf{2 5 . 0 0}$ \\
\hline \multirow{2}{*}{2} & 95.00 & 120.00 & 132.50 & 157.50 & 170.00 & 0.6431 & 1.6633 & 5524.9 & 25.00 \\
\cline { 2 - 10 } & $\mathbf{9 5 . 0 4}$ & $\mathbf{1 2 0 . 0 4}$ & $\mathbf{1 3 2 . 5 4}$ & $\mathbf{1 5 7 . 5 4}$ & $\mathbf{1 7 0 . 0 4}$ & $\mathbf{0 . 6 4 3 1}$ & $\mathbf{1 . 6 6 2 0}$ & $\mathbf{5 5 2 0 . 0}$ & $\mathbf{2 5 . 0 0}$ \\
\hline \multirow{2}{*}{3} & 95.32 & 120.32 & 132.82 & 157.82 & 170.32 & 0.6437 & 1.6572 & 5546.6 & 25.00 \\
\cline { 2 - 9 } & $\mathbf{9 5 . 3 6}$ & $\mathbf{1 2 0 . 3 6}$ & $\mathbf{1 3 2 . 8 6}$ & $\mathbf{1 5 7 . 8 6}$ & $\mathbf{1 7 0 . 3 6}$ & $\mathbf{0 . 6 4 3 7}$ & $\mathbf{1 . 6 5 6 0}$ & $\mathbf{5 5 4 2 . 0}$ & $\mathbf{2 5 . 0 0}$ \\
\hline \multirow{2}{*}{4} & 95.65 & 120.65 & 133.15 & 158.15 & 170.65 & 0.6443 & 1.6511 & 5568.2 & 25.00 \\
\cline { 2 - 10 } & $\mathbf{9 5 . 6 8}$ & $\mathbf{1 2 0 . 6 8}$ & $\mathbf{1 3 3 . 1 8}$ & $\mathbf{1 5 8 . 1 8}$ & $\mathbf{1 7 0 . 6 8}$ & $\mathbf{0 . 6 4 4 3}$ & $\mathbf{1 . 6 5 0 0}$ & $\mathbf{5 5 6 3 . 0}$ & $\mathbf{2 5 . 0 0}$ \\
\hline \multirow{2}{*}{5} & 95.97 & 120.97 & 133.47 & 158.47 & 170.97 & 0.6448 & 1.6451 & 5589.7 & 25.00 \\
\cline { 2 - 10 } & $\mathbf{9 6 . 0 1}$ & $\mathbf{1 2 1 . 0 1}$ & $\mathbf{1 3 3 . 5 1}$ & $\mathbf{1 5 8 . 5 1}$ & $\mathbf{1 7 1 . 0 1}$ & $\mathbf{0 . 6 4 4 8}$ & $\mathbf{1 . 6 4 4 0}$ & $\mathbf{5 5 8 5 . 0}$ & $\mathbf{2 5 . 0 0}$ \\
\hline
\end{tabular}




\subsubsection{Capability 3C - End channel}

The maximum relative difference between code and hand calculations of all parameters in this test case is $0.1 \%$.

Table 8. Channel \#1

\begin{tabular}{|c|c|c|c|c|c|c|c|}
\hline $\mathrm{jz}$ & tcoola & tsata & reya & vsca & rhocol & pcool & $\mathrm{cpa}$ \\
\hline \multirow{2}{*}{1} & 48.26 & 104.77 & 44928.6 & $5.629 \mathrm{E}-4$ & 988.98 & 120811 & \\
\hline & 48.26 & 104.77 & & $5.629 \mathrm{E}-4$ & 989.00 & 120800 & \\
\hline \multirow{2}{*}{2} & 48.78 & 104.29 & & $5.580 \mathrm{E}-4$ & 988.75 & 118846 & \\
\hline & 48.78 & 104.29 & & $5.580 \mathrm{E}-4$ & 988.80 & 118800 & \\
\hline \multirow{2}{*}{3} & 49.30 & 103.81 & 559 & $5.531 \mathrm{E}-4$ & 988.52 & 116881 & \\
\hline & 49.30 & 103.81 & 55 & $5.531 \mathrm{E}-4$ & 988.50 & 116900 & \\
\hline \multirow{2}{*}{4} & 49.81 & 103.32 & 563 & $5.483 \mathrm{E}-4$ & & & \\
\hline & 49. & & 563 & & & & \\
\hline & 50.33 & 102.83 & 5688 & 5.43 & & & \\
\hline 5 & 50. & & 56880.0 & 5.4 & & & \\
\hline & & & & & & & \\
\hline & & & & & & & 1.546 \\
\hline
\end{tabular}

Table 9. Channel \#2

\begin{tabular}{|c|c|c|c|c|c|c|c|}
\hline $\mathrm{jz}$ & tcoola & tsata & reya & vsca & rhocol & pcool & сра \\
\hline \multirow{2}{*}{1} & 48.17 & 104.78 & 174102.4 & $5.638 \mathrm{E}-4$ & 988.98 & 120837 & 4180.12 \\
\hline & 48.17 & 104.77 & 174100.0 & $5.638 \mathrm{E}-4$ & 989.00 & 120800 & 4180.00 \\
\hline \multirow{2}{*}{2} & 48.49 & 104.30 & 175073.1 & $5.607 \mathrm{E}-4$ & 988.84 & 118867 & 4180.21 \\
\hline & 48.49 & 104.30 & 175100.0 & $5.607 \mathrm{E}-4$ & 988.80 & 118800 & 4180.00 \\
\hline \multirow{2}{*}{3} & 48.82 & 103.81 & 176045.6 & $5.576 \mathrm{E}-4$ & 988.69 & 116897 & 4180.30 \\
\hline & \multirow{2}{*}{$\frac{48.82}{49.14}$} & 103.81 & 176000.0 & $5.576 \mathrm{E}-4$ & 988.70 & 116900 & 4180 \\
\hline \multirow{2}{*}{4} & & 103.32 & 177019.8 & $5.545 \mathrm{E}-4$ & 988.55 & 114927 & 4180.39 \\
\hline & 49.14 & 103.32 & 177000.0 & $5.545 \mathrm{E}-4$ & 988.50 & 114900 & 4180.00 \\
\hline & 49.47 & 102.83 & 177995.9 & $5.515 \mathrm{E}-4$ & 988.40 & 112958 & 4180.48 \\
\hline 5 & 49.47 & 102.83 & 178000.0 & 5.515E-4 & 988.40 & 113000 & 4180.00 \\
\hline & & & & & & & 2.454 \\
\hline & & & & & & & 2.454 \\
\hline
\end{tabular}


Table 10. Left side of fuel plate \#1

\begin{tabular}{|l|c|c|c|c|c|c|c|c|c|}
\hline jz & Tsurf & Tox-cd & Tcd-zr & Tzr-f & Tfmax & xkcp & prp4p & hcool & qc \\
\hline \multirow{2}{*}{1} & 91.66 & 108.33 & 116.66 & 133.33 & 141.66 & 0.6413 & 1.6820 & 3840.5 & 16.67 \\
\cline { 2 - 10 } & $\mathbf{9 1 . 7 0}$ & $\mathbf{1 0 8 . 3 6}$ & $\mathbf{1 1 6 . 7 0}$ & $\mathbf{1 3 3 . 3 6}$ & $\mathbf{1 4 1 . 7 0}$ & $\mathbf{0 . 6 4 1 3}$ & $\mathbf{1 . 6 8 1 0}$ & $\mathbf{3 8 3 7 . 0}$ & $\mathbf{1 6 . 6 7}$ \\
\hline \multirow{2}{*}{2} & 92.00 & 108.67 & 117.00 & 133.67 & 142.00 & 0.6419 & 1.6755 & 3856.3 & 16.67 \\
\cline { 2 - 10 } & $\mathbf{9 2 . 0 3}$ & $\mathbf{1 0 8 . 7 0}$ & $\mathbf{1 1 7 . 0 3}$ & $\mathbf{1 3 3 . 7 0}$ & $\mathbf{1 4 2 . 0 3}$ & $\mathbf{0 . 6 4 1 9}$ & $\mathbf{1 . 6 7 4 0}$ & $\mathbf{3 8 5 3 . 0}$ & $\mathbf{1 6 . 6 7}$ \\
\hline \multirow{2}{*}{3} & 92.34 & 109.00 & 117.34 & 134.00 & 142.34 & 0.6425 & 1.6690 & 3872.2 & 16.67 \\
\cline { 2 - 9 } & $\mathbf{9 2 . 3 7}$ & $\mathbf{1 0 9 . 0 4}$ & $\mathbf{1 1 7 . 3 7}$ & $\mathbf{1 3 4 . 0 4}$ & $\mathbf{1 4 2 . 3 7}$ & $\mathbf{0 . 6 4 2 5}$ & $\mathbf{1 . 6 6 8 0}$ & $\mathbf{3 8 6 9 . 0}$ & $\mathbf{1 6 . 6 7}$ \\
\hline \multirow{2}{*}{4} & 92.68 & 109.35 & 117.68 & 134.35 & 142.68 & 0.6431 & 1.6626 & 3888.0 & 16.67 \\
\cline { 2 - 9 } & $\mathbf{9 2 . 7 1}$ & $\mathbf{1 0 9 . 3 8}$ & $\mathbf{1 1 7 . 7 1}$ & $\mathbf{1 3 4 . 3 8}$ & $\mathbf{1 4 2 . 7 1}$ & $\mathbf{0 . 6 4 3 1}$ & $\mathbf{1 . 6 6 1 0}$ & $\mathbf{3 8 8 5 . 0}$ & $\mathbf{1 6 . 6 7}$ \\
\hline \multirow{2}{*}{5} & 93.02 & 109.69 & 118.02 & 134.69 & 143.02 & 0.6438 & 1.6562 & 3903.7 & 16.67 \\
\cline { 2 - 9 } & $\mathbf{9 3 . 0 6}$ & $\mathbf{1 0 9 . 7 2}$ & $\mathbf{1 1 8 . 0 6}$ & $\mathbf{1 3 4 . 7 2}$ & $\mathbf{1 4 3 . 0 6}$ & $\mathbf{0 . 6 4 3 8}$ & $\mathbf{1 . 6 5 5 0}$ & $\mathbf{3 9 0 0 . 0}$ & $\mathbf{1 6 . 6 7}$ \\
\hline
\end{tabular}

Table 11. Right side of fuel plate \#1

\begin{tabular}{|l|c|c|c|c|c|c|c|c|c|}
\hline jz & Tsurf & Tcd-ox & Tzr-cd & Tf-zr & Tfmax & xkcp & prp4p & hcool & qc \\
\hline \multirow{2}{*}{1} & 82.64 & 99.31 & 107.64 & 124.31 & 132.64 & 0.6412 & 1.6832 & 4835.0 & 16.67 \\
\cline { 2 - 10 } & $\mathbf{8 2 . 6 7}$ & $\mathbf{9 9 . 3 3}$ & $\mathbf{1 0 7 . 6 7}$ & $\mathbf{1 2 4 . 3 3}$ & $\mathbf{1 3 2 . 6 7}$ & $\mathbf{0 . 6 4 1 2}$ & $\mathbf{1 . 6 8 2 0}$ & $\mathbf{4 8 3 1 . 0}$ & $\mathbf{1 6 . 6 7}$ \\
\hline \multirow{2}{*}{2} & 82.88 & 99.54 & 107.88 & 124.54 & 132.88 & 0.6416 & 1.6791 & 4847.6 & 16.67 \\
\cline { 2 - 10 } & $\mathbf{8 2 . 9 0}$ & $\mathbf{9 9 . 5 7}$ & $\mathbf{1 0 7 . 9 0}$ & $\mathbf{1 2 4 . 5 7}$ & $\mathbf{1 3 2 . 9 0}$ & $\mathbf{0 . 6 4 1 6}$ & $\mathbf{1 . 6 7 8 0}$ & $\mathbf{4 8 4 4 . 0}$ & $\mathbf{1 6 . 6 7}$ \\
\hline \multirow{2}{*}{3} & 83.11 & 99.78 & 108.11 & 124.78 & 133.11 & 0.6420 & 1.6750 & 4860.2 & 16.67 \\
\cline { 2 - 10 } & $\mathbf{8 3 . 1 4}$ & $\mathbf{9 9 . 8 1}$ & $\mathbf{1 0 8 . 1 4}$ & $\mathbf{1 2 4 . 8 1}$ & $\mathbf{1 3 3 . 1 4}$ & $\mathbf{0 . 6 4 2 0}$ & $\mathbf{1 . 6 7 4 0}$ & $\mathbf{4 8 5 6 . 0}$ & $\mathbf{1 6 . 6 7}$ \\
\hline \multirow{2}{*}{4} & 83.35 & 100.01 & 108.35 & 125.01 & 133.35 & 0.6423 & 1.6709 & 4872.7 & 16.67 \\
\cline { 2 - 10 } & $\mathbf{8 3 . 3 8}$ & $\mathbf{1 0 0 . 0 4}$ & $\mathbf{1 0 8 . 3 8}$ & $\mathbf{1 2 5 . 0 4}$ & $\mathbf{1 3 3 . 3 8}$ & $\mathbf{0 . 6 4 2 3}$ & $\mathbf{1 . 6 7 0 0}$ & $\mathbf{4 8 6 9 . 0}$ & $\mathbf{1 6 . 6 7}$ \\
\hline \multirow{2}{*}{5} & 83.58 & 100.25 & 108.58 & 125.25 & 133.58 & 0.6427 & 1.6668 & 4885.3 & 16.67 \\
\cline { 2 - 10 } & $\mathbf{8 3 . 6 1}$ & $\mathbf{1 0 0 . 2 8}$ & $\mathbf{1 0 8 . 6 1}$ & $\mathbf{1 2 5 . 2 8}$ & $\mathbf{1 3 3 . 6 1}$ & $\mathbf{0 . 6 4 2 7}$ & $\mathbf{1 . 6 6 5 0}$ & $\mathbf{4 8 8 1 . 0}$ & $\mathbf{1 6 . 6 7}$ \\
\hline
\end{tabular}

\subsubsection{Capability 3D - Fin option}

The maximum relative difference between code and hand calculations of all parameters in this test case is $0.09 \%$.

Table 12. Channel \#1

\begin{tabular}{|c|c|c|c|c|c|c|c|}
\hline jz & tcoola & tsata & reya & vsca & rhocol & pcool & сра \\
\hline \multirow[b]{2}{*}{1} & 47.31 & 104.85 & 3495 & $5.722 \mathrm{E}-4$ & 989.41 & 121161 & \\
\hline & 47.31 & 104.85 & & $5.722 \mathrm{E}-4$ & 989.40 & 121200 & \\
\hline \multirow{2}{*}{2} & 47.91 & 104.35 & & $5.664 \mathrm{E}-4$ & 989.15 & 119125 & \\
\hline & 47.91 & 104.36 & & $5.664 \mathrm{E}-4$ & 989.20 & 119100 & \\
\hline \multirow{2}{*}{3} & 48.50 & 103.85 & & $5.606 \mathrm{E}-4$ & 988.89 & 117090 & \\
\hline & 48.50 & 103.86 & 356 & $5.606 \mathrm{E}-4$ & 988.90 & 117100 & \\
\hline \multirow{2}{*}{4} & 49.10 & 10 & 360 & $5.549 \mathrm{E}-4$ & & & \\
\hline & 49. & & 360 & 5.5 & & & \\
\hline & 49.70 & & 364 & 5.49 & & & \\
\hline 5 & 49.70 & 102.83 & 36410.0 & 5.49 & 98 & 113000 & 4181.00 \\
\hline & & & & & & & 2.000 \\
\hline & & & & & & & 2.000 \\
\hline
\end{tabular}


Table 13. Left side of fuel plate \#1

\begin{tabular}{|l|c|c|c|c|c|c|c|c|c|}
\hline jz & Tsurf & Tox-cd & Tcd-zr & Tzr-f & Tfmax & xkcp & prp4p & hcool & qc \\
\hline \multirow{2}{*}{1} & 75.35 & 83.68 & 96.18 & 121.18 & 133.68 & 0.6401 & 1.6943 & 2972.2 & 8.33 \\
\cline { 2 - 10 } & $\mathbf{7 5 . 3 7}$ & $\mathbf{8 3 . 7 0}$ & $\mathbf{9 6 . 2 0}$ & $\mathbf{1 2 1 . 2 0}$ & $\mathbf{1 3 3 . 7 0}$ & $\mathbf{0 . 6 4 0 1}$ & $\mathbf{1 . 6 9 3 0}$ & $\mathbf{2 9 7 0 . 0}$ & $\mathbf{8 . 3 3}$ \\
\hline \multirow{2}{*}{2} & 75.81 & 84.14 & 96.64 & 121.64 & 134.14 & 0.6408 & 1.6866 & 2986.6 & 8.33 \\
\cline { 2 - 10 } & $\mathbf{7 5 . 8 3}$ & $\mathbf{8 4 . 1 6}$ & $\mathbf{9 6 . 6 6}$ & $\mathbf{1 2 1 . 6 6}$ & $\mathbf{1 3 4 . 1 6}$ & $\mathbf{0 . 6 4 0 8}$ & $\mathbf{1 . 6 8 5 0}$ & $\mathbf{2 9 8 4 . 0}$ & $\mathbf{8 . 3 3}$ \\
\hline \multirow{2}{*}{3} & 76.27 & 84.61 & 97.11 & 122.11 & 134.61 & 0.6416 & 1.6789 & 3001.0 & 8.33 \\
\cline { 2 - 10 } & $\mathbf{7 6 . 3 0}$ & $\mathbf{8 4 . 6 3}$ & $\mathbf{9 7 . 1 3}$ & $\mathbf{1 2 2 . 1 3}$ & $\mathbf{1 3 4 . 6 3}$ & $\mathbf{0 . 6 4 1 6}$ & $\mathbf{1 . 6 7 8 0}$ & $\mathbf{2 9 9 9 . 0}$ & $\mathbf{8 . 3 3}$ \\
\hline \multirow{2}{*}{4} & 76.74 & 85.07 & 97.57 & 122.57 & 135.07 & 0.6423 & 1.6714 & 3015.3 & 8.33 \\
\cline { 2 - 10 } & $\mathbf{7 6 . 7 6}$ & $\mathbf{8 5 . 1 0}$ & $\mathbf{9 7 . 6 0}$ & $\mathbf{1 2 2 . 6 0}$ & $\mathbf{1 3 5 . 1 0}$ & $\mathbf{0 . 6 4 2 3}$ & $\mathbf{1 . 6 7 0 0}$ & $\mathbf{3 0 1 3 . 0}$ & $\mathbf{8 . 3 3}$ \\
\hline \multirow{2}{*}{5} & 77.21 & 85.54 & 98.04 & 123.04 & 135.54 & 0.6430 & 1.6639 & 3029.6 & 8.33 \\
\cline { 2 - 10 } & $\mathbf{7 7 . 2 3}$ & $\mathbf{8 5 . 5 6}$ & $\mathbf{9 8 . 0 6}$ & $\mathbf{1 2 3 . 0 6}$ & $\mathbf{1 3 5 . 5 6}$ & $\mathbf{0 . 6 4 3 0}$ & $\mathbf{1 . 6 6 3 0}$ & $\mathbf{3 0 2 7 . 0}$ & $\mathbf{8 . 3 3}$ \\
\hline
\end{tabular}

\subsubsection{Capability 3E - Viscosity effect on flow rate}

The maximum relative difference between code and hand calculations of all parameters in this test case is $0.11 \%$.

Table 14. Channel \#1

\begin{tabular}{|c|c|c|c|c|c|c|c|}
\hline jz & tcoola & tsata & reya & vsca & rhocol & pcool & сра \\
\hline \multirow{2}{*}{1} & 46.31 & 104.79 & 6863 & $5.823 \mathrm{E}-4$ & 989.84 & 120912 & \\
\hline & 46.31 & 104.79 & & $5.823 \mathrm{E}-4$ & 989.80 & 120900 & \\
\hline \multirow{2}{*}{2} & 46.91 & 104.31 & & $5.762 \mathrm{E}-4$ & 989.58 & 118926 & \\
\hline & 46.91 & 104.31 & & $5.762 \mathrm{E}-4$ & 989.60 & 118900 & \\
\hline \multirow{2}{*}{3} & 47.51 & 103.82 & & $5.703 E-4$ & 989.33 & 116941 & \\
\hline & 47.51 & 103.82 & 700 & $5.703 \mathrm{E}-4$ & 989.30 & 116900 & \\
\hline \multirow{2}{*}{4} & 48.11 & 103.33 & 708 & $5.644 \mathrm{E}-4$ & 989.07 & & \\
\hline & 48.11 & 103. & 708 & 5.6 & & & \\
\hline ᄃ & 48.71 & 102. & 7153 & 5.58 & 98 & 112 & \\
\hline 5 & 48.71 & 102.83 & 71530.0 & 5.58 & 98 & 113 & 41 \\
\hline & & & & & & & \\
\hline & & & & & & & 1.998 \\
\hline
\end{tabular}


Table 15. Channel \#2

\begin{tabular}{|c|c|c|c|c|c|c|c|}
\hline $\mathrm{jz}$ & tcoola & tsata & reya & vsca & rhocol & pcool & \\
\hline \multirow[b]{2}{*}{1} & 46.61 & 104.79 & 591872 & $5.792 \mathrm{E}-4$ & 989.84 & 120912 & \\
\hline & 46.61 & 104.79 & & $5.792 \mathrm{E}-4$ & 989.80 & 120900 & \\
\hline \multirow{2}{*}{2} & 47.80 & 104.31 & & $5.674 \mathrm{E}-4$ & 989.33 & 118926 & \\
\hline & 47.80 & 104.31 & & $5.674 \mathrm{E}-4$ & 989.30 & 118900 & \\
\hline \multirow{2}{*}{3} & 49.00 & 103.82 & 720 & $5.559 \mathrm{E}-4$ & 988.81 & 116940 & \\
\hline & 49.00 & 103.82 & 720 & $5.559 \mathrm{E}-4$ & 988.80 & 116900 & \\
\hline \multirow{2}{*}{4} & 50.19 & 103 & $7355^{\prime}$ & $5.448 \mathrm{E}-4$ & 988.27 & 114955 & \\
\hline & 50. & & & 5.4 & 988 & & \\
\hline 5 & 51.39 & 102.83 & 7503 & 5.34 & 987 & & \\
\hline 5 & 51.39 & 102.83 & 75030.0 & 5.34 & 987.70 & 113 & 4181.00 \\
\hline & & & & & & & 2.004 \\
\hline & & & & & & & 2.00 \\
\hline
\end{tabular}

Table 16. Left side of fuel plate \#1

\begin{tabular}{|l|c|c|c|c|c|c|c|}
\hline jz & Tsurf & Tcd-f & Tfmax & xkcp & prp4p & hcool & qc \\
\hline \multirow{2}{*}{1} & 100.18 & 112.68 & 125.18 & 0.6389 & 1.7074 & 4641.3 & 25.00 \\
\cline { 2 - 8 } & $\mathbf{1 0 0 . 2 1}$ & $\mathbf{1 1 2 . 7 1}$ & $\mathbf{1 2 5 . 2 1}$ & $\mathbf{0 . 6 3 8 9}$ & $\mathbf{1 . 7 0 6 0}$ & $\mathbf{4 6 3 8 . 0}$ & $\mathbf{2 5 . 0 0}$ \\
\hline \multirow{2}{*}{2} & 100.51 & 113.01 & 125.51 & 0.6396 & 1.6995 & 4664.1 & 25.00 \\
\cline { 2 - 8 } & $\mathbf{1 0 0 . 5 5}$ & $\mathbf{1 1 3 . 0 5}$ & $\mathbf{1 2 5 . 5 5}$ & $\mathbf{0 . 6 3 9 6}$ & $\mathbf{1 . 6 9 8 0}$ & $\mathbf{4 6 6 1 . 0}$ & $\mathbf{2 5 . 0 0}$ \\
\hline \multirow{2}{*}{3} & 100.85 & 113.35 & 125.85 & 0.6404 & 1.6917 & 4686.8 & 25.00 \\
\cline { 2 - 8 } & $\mathbf{1 0 0 . 8 9}$ & $\mathbf{1 1 3 . 3 9}$ & $\mathbf{1 2 5 . 8 9}$ & $\mathbf{0 . 6 4 0 4}$ & $\mathbf{1 . 6 9 0 0}$ & $\mathbf{4 6 8 3 . 0}$ & $\mathbf{2 5 . 0 0}$ \\
\hline \multirow{2}{*}{4} & 101.19 & 113.69 & 126.19 & 0.6411 & 1.6840 & 4709.5 & 25.00 \\
\cline { 2 - 8 } & $\mathbf{1 0 1 . 2 3}$ & $\mathbf{1 1 3 . 7 3}$ & $\mathbf{1 2 6 . 2 3}$ & $\mathbf{0 . 6 4 1 1}$ & $\mathbf{1 . 6 8 3 0}$ & $\mathbf{4 7 0 6 . 0}$ & $\mathbf{2 5 . 0 0}$ \\
\hline \multirow{2}{*}{5} & 101.54 & 114.04 & 126.54 & 0.6418 & 1.6764 & 4732.1 & 25.00 \\
\cline { 2 - 8 } & $\mathbf{1 0 1 . 5 8}$ & $\mathbf{1 1 4 . 0 8}$ & $\mathbf{1 2 6 . 5 8}$ & $\mathbf{0 . 6 4 1 8}$ & $\mathbf{1 . 6 7 5 0}$ & $\mathbf{4 7 2 8 . 0}$ & $\mathbf{2 5 . 0 0}$ \\
\hline
\end{tabular}

Table 17. Right side of fuel plate \#1

\begin{tabular}{|l|c|c|c|c|c|c|c|}
\hline \multirow{2}{*}{$\mathrm{z}$} & Tsurf & Tcd-f & Tfmax & xkcp & prp4p & hcool & qc \\
\hline \multirow{2}{*}{1} & 100.22 & 112.72 & 125.22 & 0.6392 & 1.7035 & 4663.2 & 25.00 \\
\cline { 2 - 8 } & $\mathbf{1 0 0 . 2 6}$ & $\mathbf{1 1 2 . 7 6}$ & $\mathbf{1 2 5 . 2 6}$ & $\mathbf{0 . 6 3 9 2}$ & $\mathbf{1 . 7 0 2 0}$ & $\mathbf{4 6 6 0 . 0}$ & $\mathbf{2 5 . 0 0}$ \\
\hline \multirow{2}{*}{2} & 100.90 & 113.40 & 125.90 & 0.6407 & 1.6879 & 4708.6 & 25.00 \\
\cline { 2 - 8 } & $\mathbf{1 0 0 . 9 4}$ & $\mathbf{1 1 3 . 4 4}$ & $\mathbf{1 2 5 . 9 4}$ & $\mathbf{0 . 6 4 0 7}$ & $\mathbf{1 . 6 8 7 0}$ & $\mathbf{4 7 0 5 . 0}$ & $\mathbf{2 5 . 0 0}$ \\
\hline \multirow{2}{*}{3} & 101.59 & 114.09 & 126.59 & 0.6422 & 1.6727 & 4753.9 & 25.00 \\
\cline { 2 - 8 } & $\mathbf{1 0 1 . 6 3}$ & $\mathbf{1 1 4 . 1 3}$ & $\mathbf{1 2 6 . 6 3}$ & $\mathbf{0 . 6 4 2 2}$ & $\mathbf{1 . 6 7 1 0}$ & $\mathbf{4 7 5 0 . 0}$ & $\mathbf{2 5 . 0 0}$ \\
\hline \multirow{2}{*}{4} & 102.29 & 114.79 & 127.29 & 0.6436 & 1.6579 & 4798.8 & 25.00 \\
\cline { 2 - 8 } & $\mathbf{1 0 2 . 3 3}$ & $\mathbf{1 1 4 . 8 3}$ & $\mathbf{1 2 7 . 3 3}$ & $\mathbf{0 . 6 4 3 6}$ & $\mathbf{1 . 6 5 6 0}$ & $\mathbf{4 7 9 5 . 0}$ & $\mathbf{2 5 . 0 0}$ \\
\hline \multirow{2}{*}{5} & 103.00 & 115.50 & 128.00 & 0.6450 & 1.6434 & 4843.6 & 25.00 \\
\cline { 2 - 8 } & $\mathbf{1 0 3 . 0 4}$ & $\mathbf{1 1 5 . 5 4}$ & $\mathbf{1 2 8 . 0 4}$ & $\mathbf{0 . 6 4 5 0}$ & $\mathbf{1 . 6 4 2 0}$ & $\mathbf{4 8 3 9 . 0}$ & $\mathbf{2 5 . 0 0}$ \\
\hline
\end{tabular}

\subsubsection{Capability 3F - Power split calculation}

The maximum relative difference between code and hand calculations of all parameters in this test case is $0.11 \%$. 
Table 18. Channel \#1

\begin{tabular}{|c|c|c|c|c|c|c|c|}
\hline jz & tcoola & tsata & reya & vsca & rhocol & pcool & \\
\hline \multirow{2}{*}{1} & 45.39 & 106.95 & 01239 & $5.918 \mathrm{E}-4$ & 990.26 & 131180 & \\
\hline & 45.39 & 106.95 & & $5.918 \mathrm{E}-4$ & 990.30 & 131200 & \\
\hline \multirow{2}{*}{2} & 46.14 & 106.02 & & $5.840 \mathrm{E}-4$ & 989.94 & 127139 & \\
\hline & 46.14 & 106.02 & & $5.840 \mathrm{E}-4$ & 989.90 & 127100 & \\
\hline \multirow{2}{*}{3} & 46.89 & 105.07 & & $5.764 \mathrm{E}-4$ & 989.62 & 123100 & \\
\hline & 46.89 & 105.07 & & $5.764 \mathrm{E}-4$ & 989.60 & 123100 & \\
\hline \multirow{2}{*}{4} & 47.65 & 104.0 & $937 !$ & $5.689 \mathrm{E}-4$ & 989.30 & & \\
\hline & 47.65 & & & 5.6 & 98 & & \\
\hline 5 & 48.41 & 103.09 & 94 & 5.61 & 988 & 115 & \\
\hline J & 48.41 & 103.09 & 94980.0 & 5.61 & 989 & 115 & 4180.00 \\
\hline & & & & & & & 2.667 \\
\hline & & & & & & & 2.667 \\
\hline
\end{tabular}

Table 19. Channel \#2

\begin{tabular}{|c|c|c|c|c|c|c|c|}
\hline jz & tcoola & tsata & reya & vsca & rhocol & pcool & сра \\
\hline \multirow{2}{*}{1} & 45.76 & 106.94 & 90718.9 & $5.879 \mathrm{E}-4$ & 990.26 & 131165 & 4179.56 \\
\hline & 45.76 & 106.94 & 90720.0 & $5.879 \mathrm{E}-4$ & 990.30 & 131200 & 4180.00 \\
\hline \multirow{2}{*}{2} & 47.26 & 106.02 & 93116.0 & $5.728 \mathrm{E}-4$ & 989.63 & 127125 & 9.90 \\
\hline & 47.25 & 106.02 & 93110.0 & $5.728 \mathrm{E}-4$ & 989.60 & 127100 & 4180.00 \\
\hline \multirow{2}{*}{3} & 48.75 & 105.07 & 95530.0 & $5.583 \mathrm{E}-4$ & 988.98 & 123087 & 4180.28 \\
\hline & 48.74 & 105.07 & 95520.0 & $5.584 \mathrm{E}-4$ & 989.00 & 123100 & 4180.00 \\
\hline \multirow{2}{*}{4} & 50.23 & 104.09 & 97960.1 & $5.444 \mathrm{E}-4$ & 988.32 & 119052 & 4180.70 \\
\hline & 50.22 & 104.09 & 97930.0 & $5.446 \mathrm{E}-4$ & 988.30 & 119100 & 4181.00 \\
\hline & 51.72 & 103.09 & 100405.7 & $5.312 \mathrm{E}-4$ & 987.65 & 115019 & 4181.16 \\
\hline 5 & 51.69 & 103.09 & 100400.0 & $5.314 \mathrm{E}-4$ & 987.70 & 115000 & 4181.00 \\
\hline ac & & & & & & & 2.667 \\
\hline & & & & & & & 2.667 \\
\hline
\end{tabular}

Table 20. Left side of fuel plate \#1

\begin{tabular}{|l|c|c|c|c|c|c|c|c|}
\hline jz & Tsurf & Tcd-f & Tfmax & xkcp & prp4p & hcool & qc & fp \\
\hline \multirow{2}{*}{1} & 81.35 & 102.22 & 112.68 & 0.6377 & 1.7198 & 5802.5 & 20.87 & 0.501 \\
\cline { 2 - 9 } & $\mathbf{8 1 . 3 8}$ & $\mathbf{1 0 2 . 2 5}$ & $\mathbf{1 1 2 . 7 0}$ & $\mathbf{0 . 6 3 7 7}$ & $\mathbf{1 . 7 1 9 0}$ & $\mathbf{5 7 9 9 . 0}$ & $\mathbf{2 0 . 8 7}$ & $\mathbf{0 . 5 0 1}$ \\
\hline \multirow{2}{*}{2} & 82.01 & 102.95 & 113.47 & 0.6386 & 1.7097 & 5838.6 & 20.94 & 0.503 \\
\cline { 2 - 9 } & $\mathbf{8 2 . 0 3}$ & $\mathbf{1 0 2 . 9 7}$ & $\mathbf{1 1 3 . 4 9}$ & $\mathbf{0 . 6 3 8 6}$ & $\mathbf{1 . 7 0 8 0}$ & $\mathbf{5 8 3 5 . 0}$ & $\mathbf{2 0 . 9 4}$ & $\mathbf{0 . 5 0 3}$ \\
\hline \multirow{2}{*}{3} & 82.66 & 103.68 & 114.27 & 0.6396 & 1.6997 & 5874.7 & 21.01 & 0.504 \\
\cline { 2 - 8 } & $\mathbf{8 2 . 6 9}$ & $\mathbf{1 0 3 . 7 0}$ & $\mathbf{1 1 4 . 3 0}$ & $\mathbf{0 . 6 3 9 6}$ & $\mathbf{1 . 6 9 8 0}$ & $\mathbf{5 8 7 0 . 0}$ & $\mathbf{2 1 . 0 1}$ & $\mathbf{0 . 5 0 4}$ \\
\hline \multirow{2}{*}{4} & 83.32 & 104.41 & 115.08 & 0.6405 & 1.6899 & 5910.9 & 21.09 & 0.506 \\
\cline { 2 - 8 } & $\mathbf{8 3 . 3 5}$ & $\mathbf{1 0 4 . 4 4}$ & $\mathbf{1 1 5 . 1 1}$ & $\mathbf{0 . 6 4 0 5}$ & $\mathbf{1 . 6 8 9 0}$ & $\mathbf{5 9 0 6 . 0}$ & $\mathbf{2 1 . 0 9}$ & $\mathbf{0 . 5 0 6}$ \\
\hline \multirow{2}{*}{5} & 83.99 & 105.16 & 115.90 & 0.6415 & 1.6802 & 5947.0 & 21.16 & 0.508 \\
\cline { 2 - 9 } & $\mathbf{8 4 . 0 2}$ & $\mathbf{1 0 5 . 1 8}$ & $\mathbf{1 1 5 . 9 2}$ & $\mathbf{0 . 6 4 1 5}$ & $\mathbf{1 . 6 7 9 0}$ & $\mathbf{5 9 4 2 . 0}$ & $\mathbf{2 1 . 1 6}$ & $\mathbf{0 . 5 0 8}$ \\
\hline
\end{tabular}


Table 21. Right side of fuel plate \#1

\begin{tabular}{|l|c|c|c|c|c|c|c|c|}
\hline jz & Tsurf & Tcd-f & Tfmax & xkcp & prp4p & hcool & qc & fp \\
\hline \multirow{2}{*}{1} & 81.50 & 102.29 & 112.68 & 0.6382 & 1.7147 & 5820.5 & 20.80 & 0.499 \\
\cline { 2 - 9 } & $\mathbf{8 1 . 5 2}$ & $\mathbf{1 0 2 . 3 2}$ & $\mathbf{1 1 2 . 7 0}$ & $\mathbf{0 . 6 3 8 2}$ & $\mathbf{1 . 7 1 4 0}$ & $\mathbf{5 8 1 6 . 0}$ & $\mathbf{2 0 . 8 0}$ & $\mathbf{0 . 4 9 9}$ \\
\hline \multirow{2}{*}{2} & 82.43 & 103.16 & 113.47 & 0.6400 & 1.6950 & 5892.1 & 20.73 & 0.497 \\
\cline { 2 - 9 } & $\mathbf{8 2 . 4 6}$ & $\mathbf{1 0 3 . 1 8}$ & $\mathbf{1 1 3 . 4 9}$ & $\mathbf{0 . 6 4 0 0}$ & $\mathbf{1 . 6 9 4 0}$ & $\mathbf{5 8 8 8 . 0}$ & $\mathbf{2 0 . 7 3}$ & $\mathbf{0 . 4 9 7}$ \\
\hline \multirow{2}{*}{3} & 83.38 & 104.03 & 114.27 & 0.6419 & 1.6759 & 5963.1 & 20.65 & 0.496 \\
\cline { 2 - 8 } & $\mathbf{8 3 . 4 0}$ & $\mathbf{1 0 4 . 0 6}$ & $\mathbf{1 1 4 . 3 0}$ & $\mathbf{0 . 6 4 1 9}$ & $\mathbf{1 . 6 7 5 0}$ & $\mathbf{5 9 5 8 . 0}$ & $\mathbf{2 0 . 6 5}$ & $\mathbf{0 . 4 9 6}$ \\
\hline \multirow{2}{*}{4} & 84.34 & 104.92 & 115.08 & 0.6436 & 1.6574 & 6033.6 & 20.58 & 0.494 \\
\cline { 2 - 8 } & $\mathbf{8 4 . 3 6}$ & $\mathbf{1 0 4 . 9 4}$ & $\mathbf{1 1 5 . 1 1}$ & $\mathbf{0 . 6 4 3 6}$ & $\mathbf{1 . 6 5 6 0}$ & $\mathbf{6 0 2 8 . 0}$ & $\mathbf{2 0 . 5 8}$ & $\mathbf{0 . 4 9 4}$ \\
\hline \multirow{2}{*}{5} & 85.31 & 105.82 & 115.90 & 0.6454 & 1.6394 & 6103.5 & 20.50 & 0.492 \\
\cline { 2 - 8 } & $\mathbf{8 5 . 3 2}$ & $\mathbf{1 0 5 . 8 3}$ & $\mathbf{1 1 5 . 9 2}$ & $\mathbf{0 . 6 4 5 3}$ & $\mathbf{1 . 6 3 8 0}$ & $\mathbf{6 0 9 7 . 0}$ & $\mathbf{2 0 . 5 1}$ & $\mathbf{0 . 4 9 2}$ \\
\hline
\end{tabular}

\subsubsection{Capability 3G - ONB temperature}

The core power of the base model is increased so that the ONB is detected at two axial nodes. The obtained temperature profiles and the list of these ONB nodes are provided in Table 22.

The maximum relative difference between the temperatures obtained by code and hand calculation in this test case is $0.05 \%$.

Table 22. Temperature profiles of channel \#1 and left side of plate \#1

\begin{tabular}{|l|c|c|c|c|c|c|c|c|c|}
\hline jz & Tcoola & Tsata & Tonb & Tsurf & Tox-cd & Tcd-zr & Tzr-f & Tfmax & ONB \\
\hline \multirow{2}{*}{1} & 46.86 & 104.81 & 111.61 & 109.37 & 138.54 & 153.12 & 182.29 & 196.87 & No \\
\cline { 2 - 10 } & $\mathbf{4 6 . 8 6}$ & $\mathbf{1 0 4 . 7 9}$ & $\mathbf{1 1 1 . 6 3}$ & $\mathbf{1 0 9 . 4 2}$ & $\mathbf{1 3 8 . 5 8}$ & $\mathbf{1 5 3 . 1 7}$ & $\mathbf{1 8 2 . 3 3}$ & $\mathbf{1 9 6 . 9 2}$ & No \\
\hline \multirow{2}{*}{2} & 47.56 & 104.33 & 111.18 & 109.72 & 138.88 & 153.47 & 182.63 & 197.22 & No \\
\cline { 2 - 10 } & $\mathbf{4 7 . 5 6}$ & $\mathbf{1 0 4 . 3 1}$ & $\mathbf{1 1 1 . 2 0}$ & $\mathbf{1 0 9 . 7 6}$ & $\mathbf{1 3 8 . 9 3}$ & $\mathbf{1 5 3 . 5 1}$ & $\mathbf{1 8 2 . 6 8}$ & $\mathbf{1 9 7 . 2 6}$ & No \\
\hline \multirow{2}{*}{3} & 48.26 & 103.83 & 110.75 & 110.07 & 139.23 & 153.82 & 182.98 & 197.57 & No \\
\cline { 2 - 10 } & $\mathbf{4 8 . 2 6}$ & $\mathbf{1 0 3 . 8 2}$ & $\mathbf{1 1 0 . 7 7}$ & $\mathbf{1 1 0 . 1 2}$ & $\mathbf{1 3 9 . 2 8}$ & $\mathbf{1 5 3 . 8 7}$ & $\mathbf{1 8 3 . 0 3}$ & $\mathbf{1 9 7 . 6 2}$ & No \\
\hline \multirow{2}{*}{4} & 48.95 & 103.34 & 110.31 & 110.42 & 139.59 & 154.17 & 183.34 & 197.92 & Yes \\
\cline { 2 - 10 } & $\mathbf{4 8 . 9 5}$ & $\mathbf{1 0 3 . 3 3}$ & $\mathbf{1 1 0 . 3 3}$ & $\mathbf{1 1 0 . 4 7}$ & $\mathbf{1 3 9 . 6 4}$ & $\mathbf{1 5 4 . 2 2}$ & $\mathbf{1 8 3 . 3 9}$ & $\mathbf{1 9 7 . 9 7}$ & Yes \\
\hline \multirow{2}{*}{5} & 49.65 & 102.83 & 109.86 & 110.78 & 139.95 & 154.53 & 183.70 & 198.28 & Yes \\
\cline { 2 - 10 } & $\mathbf{4 9 . 6 5}$ & $\mathbf{1 0 2 . 8 3}$ & $\mathbf{1 0 9 . 8 9}$ & $\mathbf{1 1 0 . 8 3}$ & $\mathbf{1 4 0 . 0 0}$ & $\mathbf{1 5 4 . 5 8}$ & $\mathbf{1 8 3 . 7 5}$ & $\mathbf{1 9 8 . 3 3}$ & Yes \\
\hline
\end{tabular}

\subsection{Comparison between STAT7 and PLTEMP calculations}

As mentioned in Section 3.4, the comparison between STAT7 and PLTEMP codes is performed by matching the total core flowrate of the test models (Figure 2). It can be seen in Figure 8 and Figure 9 that the temperatures calculated by the codes agree very well to each other. 


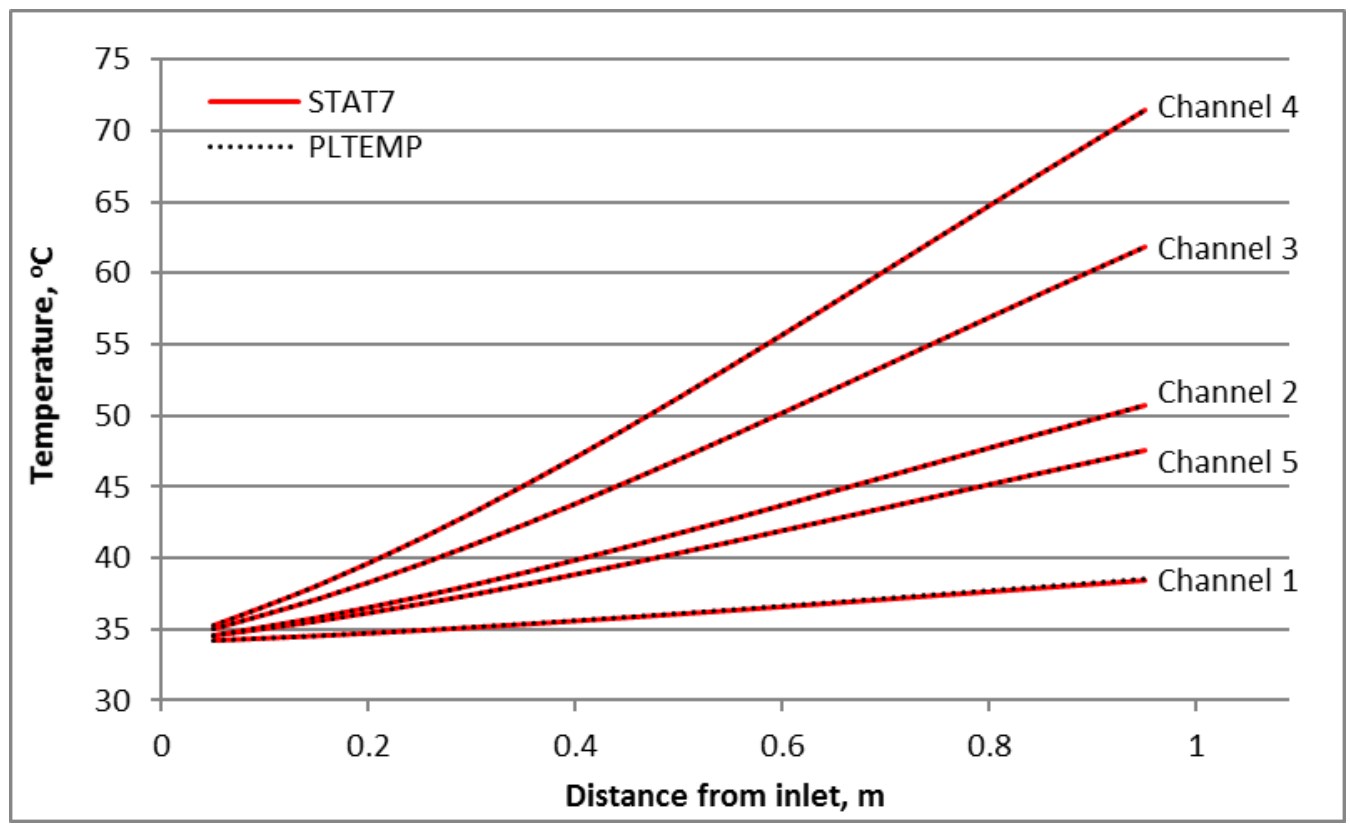

Figure 8. Coolant temperature profiles

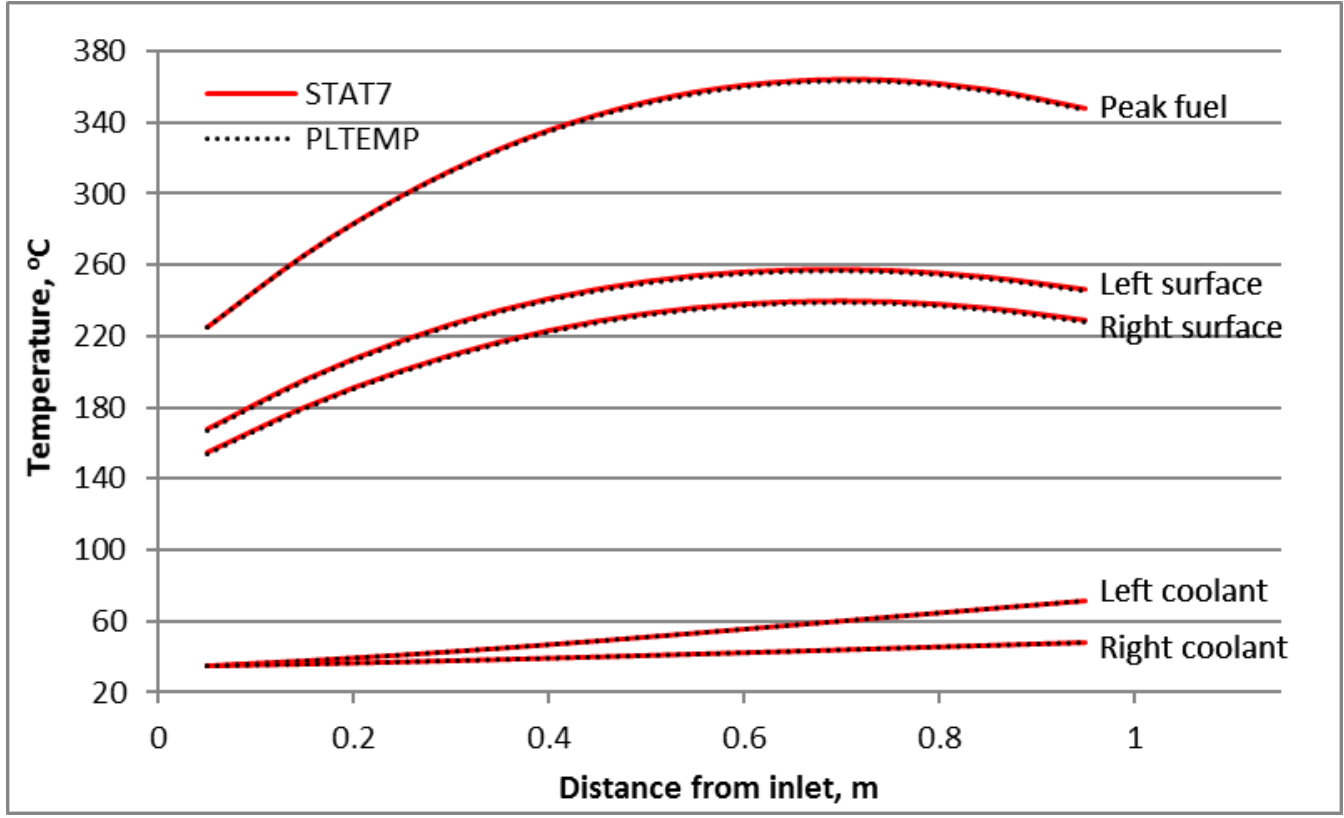

Figure 9. Temperature profiles corresponding to fuel plate \#4

The comprehensive comparisons including all thermal hydraulic parameters are performed using node-to-node comparison for all channels. It should be noticed that the codes used different generators for coolant properties. Consequently, the coolant properties show differences up to $0.73 \%$ (Table 23) which could be responsible for the differences in other data. Nevertheless, a good agreement within $0.75 \%$ is achieved for all thermal hydraulic parameters belonging to the fuel core region as can be seen in Table 24. 
The obtained bypass flowrates, however, present a difference of 3.1\%, which does indicate an issue in the STAT7 calculations if this particular thermal hydraulics capability would be utilized (it has not been utilized to date). As an attempt to investigate this problem, the existing test models (Figure 2) are rerun without the fins. The results included in Table 24 show a good agreement between the bypass flowrates calculated by the codes when the fins have been removed. Therefore, it can be concluded that the bypass flowrate is calculated correctly if the fuel plates do not have fins, and incorrectly if fins are present.

It should also be clarified that both existing and prospective applications of STAT7 code in the steadystate thermal-hydraulic analyses at MITR do not use bypass capability in the same way of current test models. Instead of letting the code calculate bypass flowrate, these analyses have been specifying the flow distribution in the core region and the bypass channel as an input parameter named "coolant flow factor". In the other words, although the issue of bypass flowrate calculation with the present of fins will need to be resolved, it does not affect the application of STAT7 in the thermal hydraulic analyses performed to date and will be noted as a limitation of the code until corrected.

Table 23. Node-to-node comparison of coolant properties reported by STAT7 and PLTEMP

\begin{tabular}{|c|c|c|c|}
\hline \multirow{2}{*}{ Channel } & \multicolumn{3}{|c|}{ Max. relative difference, \% } \\
\cline { 2 - 4 } & Viscosity & Thermal Conductivity & Density \\
\hline 1 & 0.05 & 0.73 & 0.02 \\
\hline 2 & 0.66 & 0.50 & 0.05 \\
\hline 3 & 0.67 & 0.44 & 0.06 \\
\hline 4 & 0.59 & 0.50 & 0.07 \\
\hline 5 & 0.55 & 0.54 & 0.04 \\
\hline
\end{tabular}

Table 24. Comparison of thermal hydraulic data obtained with STAT7 and PLTEMP

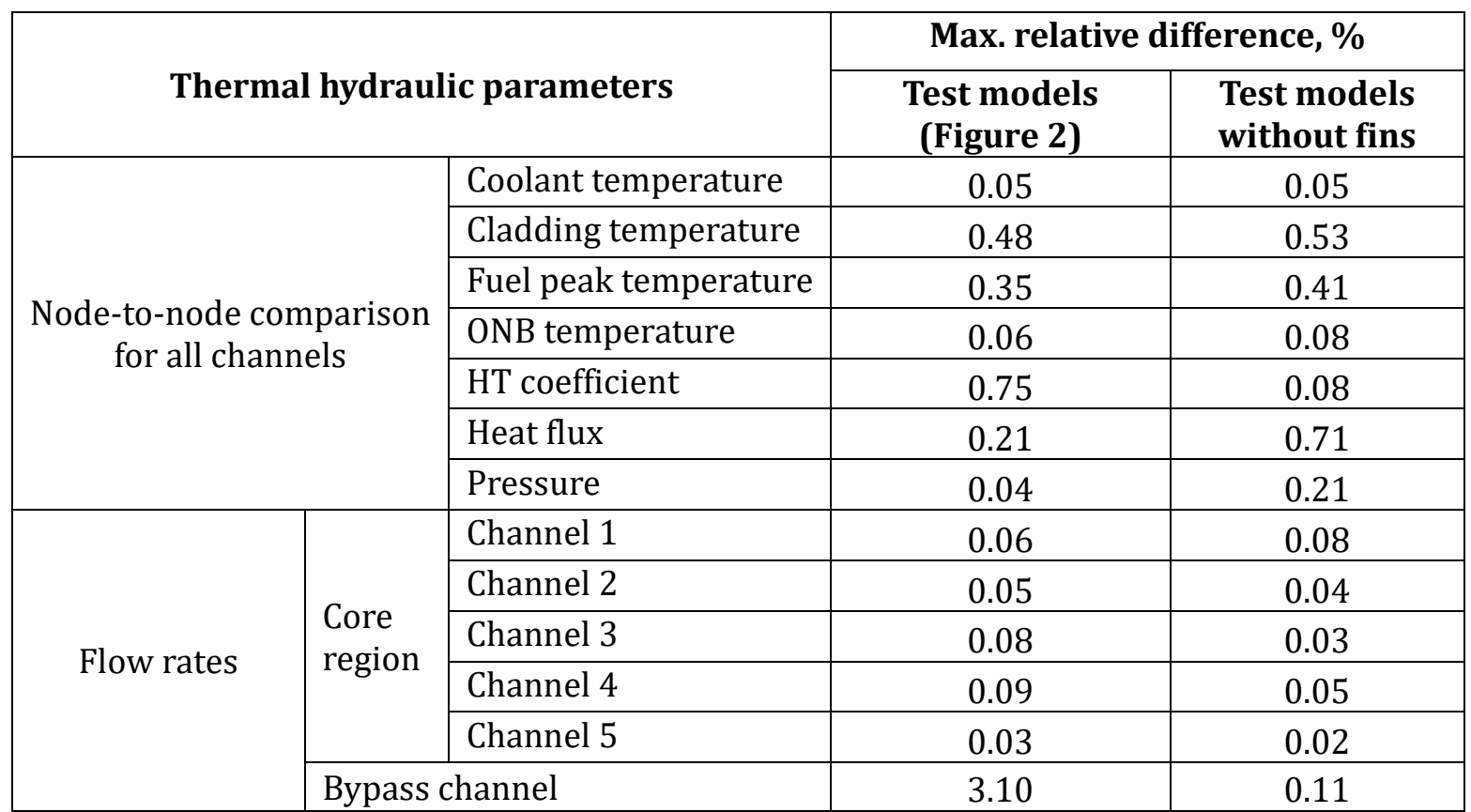




\section{Conclusions}

The results and discussions presented above lead to the following conclusions:

- The random number generator embedded in the code is suitable to be used for the statistical sampling.

- The coolant properties generated by the code agree well with data provided by NIST/ASME steam formulas within the maximum relative difference of $0.5 \%$.

- The key thermal hydraulic capabilities were verified independently using hand calculations. The relative differences between the code and hand calculations are less than $0.12 \%$ for all test cases.

- A comprehensive comparison was made between the STAT7 and PLTEMP using a five-channel test-problem involving all thermal hydraulic capabilities. The results show that the codes agree well with each other within $0.75 \%$ for all thermal hydraulic parameters corresponding to the core region.

- The difference of 3.1\% in bypass flowrate indicates an issue with STAT7 calculations when both fin and bypass capabilities are involved. This problem, however, does not affect the current and planned application of STAT7 where the flow distribution in core region and bypass channel is specified as an input parameter. 


\section{Acknowledgement}

Discussions with Floyd Dunn, the developer of STAT7, are gratefully acknowledged regarding understanding the framework and function of STAT7.

This work was sponsored by the U.S. Department of Energy, Office of Material Management and Minimization in the U.S. National Nuclear Security Administration Office of Defense Nuclear Nonproliferation under Contract DE-AC02-06CH11357. 


\section{References}

[1] Floyd E. Dunn, Lin-wen Hu, and Erik Wilson. The STAT7 Code for Statistical Propagation of Uncertainties In Steady-State Thermal Hydraulics Analysis of Plate-Fueled Reactors, ANL/RTR/TM-16/7, Dec. 2016.

[2] A. H. Harvey and E. W. Lemmon, NIST/ASME Steam Formulations for Generic and Scientific Uses. NIST Standard Reference Database 10, Version 3.0, 2013.

[3] A. P. Olson, M. Kalimullah, and E. E. Feldman. A User's Guide to the PLTEMP/ANL Code, ANL/RERTR/TM-11-22 Rev. 2, Version 4.2, July 25, 2016.

[4] T. C. Carnavos, "Heat Transfer Performance of Internally Finned Tubes in Turbulent Flow," Heat Transfer Engineering, 1: 4, 32-37, 1980.

[5] NIST/SEMATECH e-Handbook of Statistical Methods, http://www.itl.nist.gov/div898/handbook/, Feb. 2018. 


\section{Appendix A: Acceptance Testing Criteria}

Unlike the V\&V work described in the Section 4 above, the acceptance test is to confirm that a newly compiled or installed code version will provide the same results as those obtained with STAT7 Version 1.0, which is considered by the current $\mathrm{V} \& \mathrm{~V}$. This section presents the acceptance values and tolerances for key output variables that need to be monitored in the acceptance test. The acceptance values are to ensure the duplication of the output data, while the tolerances are to allow insignificant differences caused by the differences in the compilers or host operating systems.

Because the channels in STAT7 models are not independent from each other, errors in calculation data at a location will lead to errors at other locations. Therefore, the aggregated tests only need to check the output data of one channel and a half of a fuel plate (left or right) at an axial node near the outlet. The checking locations and acceptance values for each test case are shown in Table 25. The tolerances are set based on the last significant digit of the corresponding acceptance value printed out by the code.

Table 25. Accepted criteria for all test cases

\begin{tabular}{|c|c|c|c|c|c|c|c|c|c|c|}
\hline \multirow{2}{*}{ Output variables } & \multicolumn{9}{|c|}{ Acceptance values } & \multirow{3}{*}{ Tolerance } \\
\hline & Case 01 & Case 02 & Case 03 & Case 04 & Case 05 & Case 06 & Case 07 & Case 08 & Case 09 & \\
\hline Channel data point* & Ch1-N4 & Ch1-N4 & Ch2-N4 & Ch1-N4 & Ch2-N4 & Ch2-N4 & Ch1-N4 & Ch3-N9 & Ch3-N9 & \\
\hline Coolant temp., ${ }^{\circ} \mathrm{C}$ & 49.10 & 50.75 & 49.14 & 49.10 & 50.19 & 50.22 & 48.95 & 58.57 & 54.81 & 0.01 \\
\hline Saturation temp., ${ }^{\circ} \mathrm{C}$ & 103.33 & 103.34 & 103.32 & 103.35 & 103.33 & 104.09 & 103.33 & 100.41 & 100.40 & 0.01 \\
\hline $\operatorname{Re}$ & $7.208 \mathrm{E}+4$ & $8.892 \mathrm{E}+4$ & $1.770 \mathrm{E}+5$ & $3.604 \mathrm{E}+4$ & $7.356 \mathrm{E}+4$ & $9.793 \mathrm{E}+4$ & $7.190 \mathrm{E}+4$ & $2.130 \mathrm{E}+4$ & $4.745 \mathrm{E}+4$ & $1.0 \mathrm{E}+1$ \\
\hline Viscosity, $\mathrm{Pa}^{*} \mathrm{~s}$ & $5.549 \mathrm{E}-4$ & $5.398 \mathrm{E}-4$ & $5.545 \mathrm{E}-4$ & $5.549 \mathrm{E}-4$ & $5.448 \mathrm{E}-4$ & $5.446 \mathrm{E}-4$ & $5.563 \mathrm{E}-4$ & $4.765 \mathrm{E}-4$ & $5.052 \mathrm{E}-4$ & $1.0 \mathrm{E}-7$ \\
\hline Density, $\mathrm{kg} / \mathrm{m} 3$ & $9.885 \mathrm{E}+2$ & $9.878 \mathrm{E}+2$ & $9.885 \mathrm{E}+2$ & $9.885 \mathrm{E}+2$ & $9.880 \mathrm{E}+2$ & $9.880 \mathrm{E}+2$ & $9.886 \mathrm{E}+2$ & $9.840 \mathrm{E}+2$ & $9.858 \mathrm{E}+2$ & $1.0 \mathrm{E}-1$ \\
\hline Pressure, $\mathrm{Pa}$ & $1.140 \mathrm{E}+5$ & $1.140 \mathrm{E}+5$ & $1.139 \mathrm{E}+5$ & $1.140 \mathrm{E}+5$ & $1.140 \mathrm{E}+5$ & $1.170 \mathrm{E}+5$ & $1.140 \mathrm{E}+5$ & $1.028 \mathrm{E}+5$ & $1.028 \mathrm{E}+5$ & $1.0 \mathrm{E}+2$ \\
\hline Specific heat capacity, $\mathrm{J} /\left(\mathrm{kg}^{\circ} \mathrm{C}\right)$ & $4.180 \mathrm{E}+3$ & $4.181 \mathrm{E}+3$ & $4.180 \mathrm{E}+3$ & $4.180 \mathrm{E}+3$ & $4.181 \mathrm{E}+3$ & $4.181 \mathrm{E}+3$ & $4.180 \mathrm{E}+3$ & $4.184 \mathrm{E}+3$ & $4.182 \mathrm{E}+3$ & $1.0 \mathrm{E}+0$ \\
\hline Flow area, $\mathrm{m}^{2}$ & $2.000 \mathrm{E}-3$ & $2.000 \mathrm{E}-3$ & $2.000 \mathrm{E}-3$ & $2.100 \mathrm{E}-3$ & $2.000 \mathrm{E}-3$ & $2.000 \mathrm{E}-3$ & $2.000 \mathrm{E}-3$ & $7.200 \mathrm{E}-3$ & $8.000 \mathrm{E}-3$ & $1.0 \mathrm{E}-6$ \\
\hline Hydraulic diameter, m & $4.000 \mathrm{E}-2$ & $4.000 \mathrm{E}-2$ & $8.000 \mathrm{E}-2$ & $2.100 \mathrm{E}-2$ & $4.000 \mathrm{E}-2$ & $4.000 \mathrm{E}-2$ & $4.000 \mathrm{E}-2$ & $1.800 \mathrm{E}-2$ & $4.000 \mathrm{E}-2$ & $1.0 \mathrm{E}-5$ \\
\hline Mass flowrate, $\mathrm{kg} / \mathrm{s}$ & $2.000 \mathrm{E}+0$ & $2.400 \mathrm{E}+0$ & $2.454 \mathrm{E}+0$ & $2.000 \mathrm{E}+0$ & $2.004 \mathrm{E}+0$ & $2.667 \mathrm{E}+0$ & $2.000 \mathrm{E}+0$ & $4.060 \mathrm{E}+0$ & $4.795 \mathrm{E}+0$ & $1.0 \mathrm{E}-3$ \\
\hline Plate data point* & $1 L-N 4$ & $1 L-N 4$ & $1 R-N 4$ & $1 L-N 4$ & $1 R-N 4$ & $1 R-N 4$ & $1 L-N 4$ & 2R-N9 & $2 R-N 9$ & \\
\hline Clad surface temp., ${ }^{\circ} \mathrm{C}$ & 101.77 & 95.68 & 83.38 & 76.76 & 102.33 & 84.36 & 110.47 & 163.17 & 228.49 & 0.01 \\
\hline Oxide-clad temp., ${ }^{\circ} \mathrm{C}$ & 126.77 & 120.68 & 100.04 & 85.10 & 102.33 & 84.36 & 139.64 & 163.17 & 228.49 & 0.01 \\
\hline Clad-Zr temp., ${ }^{\circ} \mathrm{C}$ & 139.27 & 133.18 & 108.38 & 97.60 & 114.83 & 104.94 & 154.22 & 191.46 & 257.09 & 0.01 \\
\hline Zr-fuel temp., ${ }^{\circ} \mathrm{C}$ & 164.27 & 158.18 & 125.04 & 122.60 & 114.83 & 104.94 & 183.39 & 191.46 & 257.09 & 0.01 \\
\hline Peak fuel temp., ${ }^{\circ} \mathrm{C}$ & 176.77 & 170.68 & 133.38 & 135.10 & 127.33 & 115.11 & 197.97 & 219.70 & 285.93 & 0.01 \\
\hline Film thermal cond., $\mathrm{W} /(\mathrm{mK})$ & $6.423 \mathrm{E}-1$ & $6.443 \mathrm{E}-1$ & $6.423 \mathrm{E}-1$ & $6.423 \mathrm{E}-1$ & $6.436 \mathrm{E}-1$ & $6.436 \mathrm{E}-1$ & $6.421 \mathrm{E}-1$ & $6.528 \mathrm{E}-1$ & $6.488 \mathrm{E}-1$ & $1.0 \mathrm{E}-4$ \\
\hline $\operatorname{Pr}^{\wedge} 0.4$ & $1.670 \mathrm{E}+0$ & $1.650 \mathrm{E}+0$ & $1.670 \mathrm{E}+0$ & $1.670 \mathrm{E}+0$ & $1.656 \mathrm{E}+0$ & $1.656 \mathrm{E}+0$ & $1.672 \mathrm{E}+0$ & $1.562 \mathrm{E}+0$ & $1.602 \mathrm{E}+0$ & $1.0 \mathrm{E}-3$ \\
\hline Heat transfer coef., $\mathrm{W} /\left(\mathrm{m}^{2 \circ} \mathrm{C}\right)$ & $4.747 \mathrm{E}+3$ & $5.563 \mathrm{E}+3$ & $4.869 \mathrm{E}+3$ & $3.013 \mathrm{E}+3$ & $4.795 \mathrm{E}+3$ & $6.028 \mathrm{E}+3$ & $4.741 \mathrm{E}+3$ & $2.705 \mathrm{E}+3$ & $3.293 E+3$ & $1.0 \mathrm{E}+0$ \\
\hline Surface heat flux, $\mathrm{W} / \mathrm{cm}^{2}$ & $2.500 \mathrm{E}+1$ & $2.500 \mathrm{E}+1$ & $1.667 \mathrm{E}+1$ & $8.330 \mathrm{E}+0$ & $2.500 \mathrm{E}+1$ & $0.000 \mathrm{E}+0$ & $2.917 \mathrm{E}+1$ & $2.829 \mathrm{E}+1$ & $5.719 \mathrm{E}+1$ & $1.0 \mathrm{E}-2$ \\
\hline ONB temp., ${ }^{\circ} \mathrm{C}$ & $1.099 \mathrm{E}+2$ & $1.099 \mathrm{E}+2$ & $1.087 \mathrm{E}+2$ & $1.073 \mathrm{E}+2$ & $1.099 \mathrm{E}+2$ & $1.100 \mathrm{E}+2$ & $1.103 \mathrm{E}+2$ & $1.077 \mathrm{E}+2$ & $1.105 \mathrm{E}+2$ & $1.0 \mathrm{E}-1$ \\
\hline Power split & 0.500 & 0.500 & 0.500 & 0.500 & 0.500 & 0.494 & 0.500 & 0.499 & 0.504 & 0.001 \\
\hline Bypass flow rate, $\mathrm{kg} / \mathrm{s}$ & $\mathrm{N} / \mathrm{A}$ & $2.1580 \mathrm{E}+1$ & $\mathrm{~N} / \mathrm{A}$ & $\mathrm{N} / \mathrm{A}$ & $\mathrm{N} / \mathrm{A}$ & N/A & $\mathrm{N} / \mathrm{A}$ & $5.4047 \mathrm{E}+0$ & $3.3881 \mathrm{E}+0$ & $1.0 \mathrm{E}-2$ \\
\hline
\end{tabular}

* Data are provided at the middle of each axial node. Abbreviations include Ch - channel; $N$ - axial node; $L$ - left surface; and $R$

- right surface. All acceptance values are reported using the same format as in the output files. 


\section{Appendix B: STAT7 and PLTEMP Input Files}

\section{STAT7 Input}

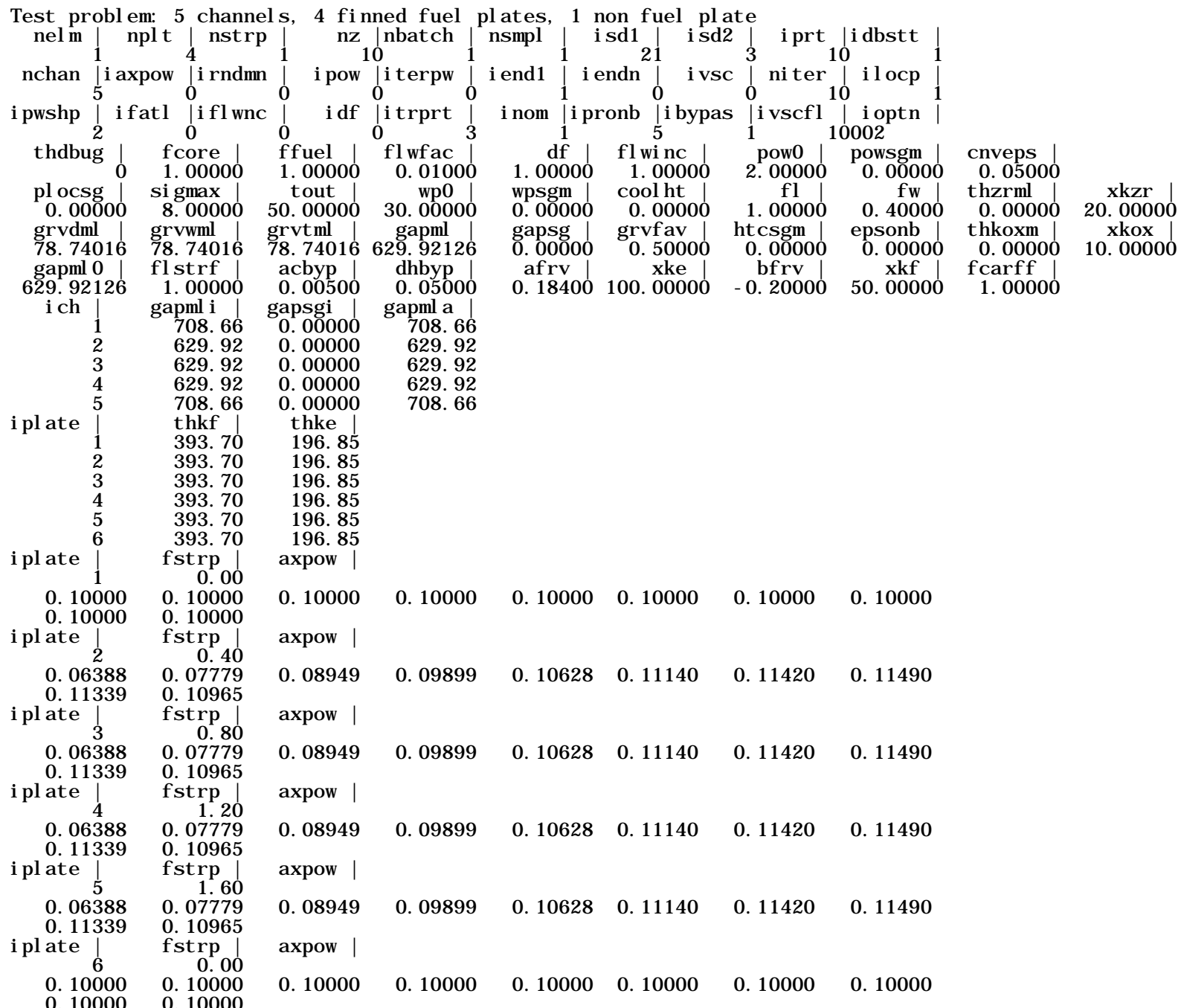




\section{PLTEMP Input}

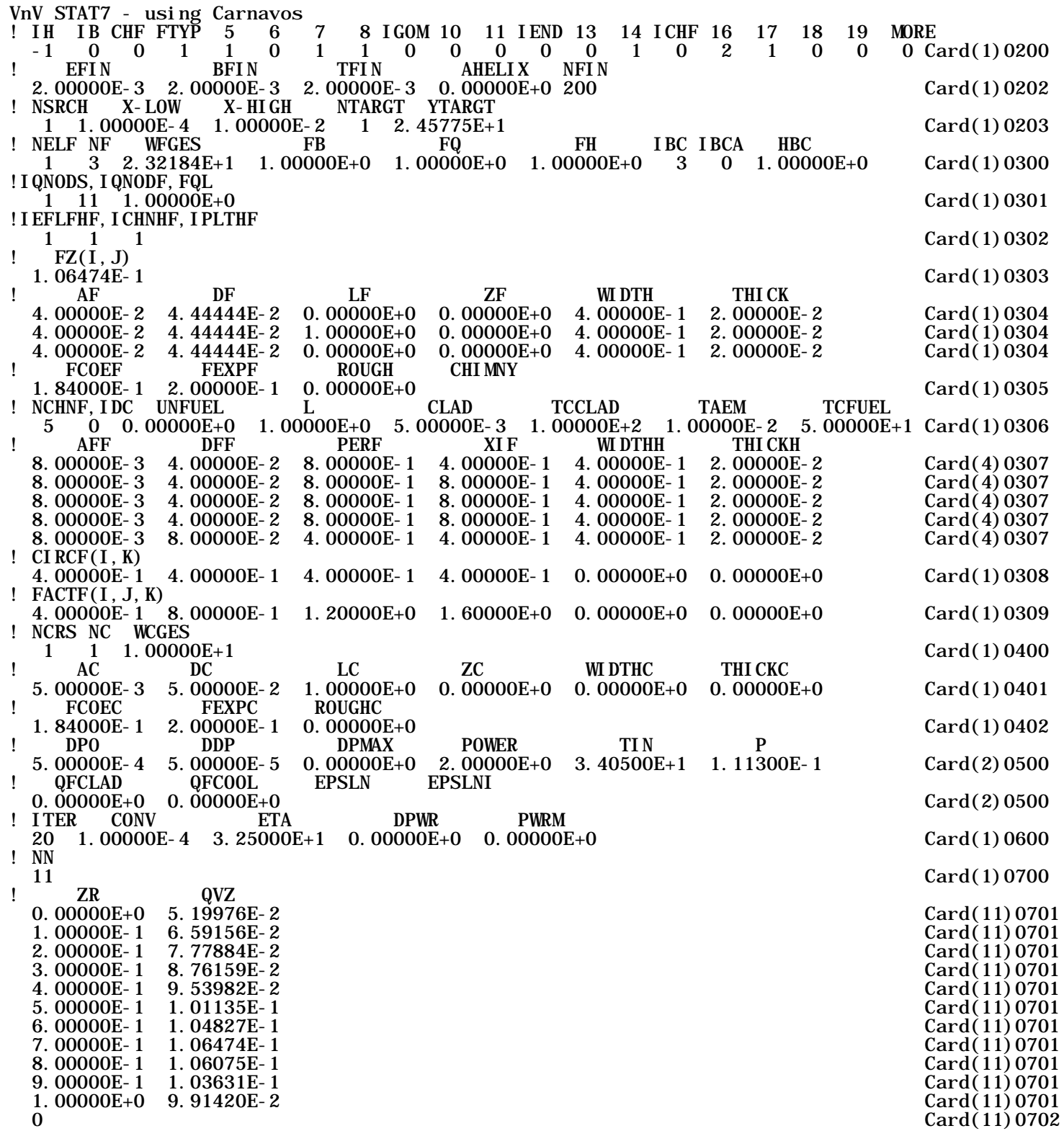


(This page left intentionally blank) 


\section{Argonne}

Nuclear Science \& Engineering Division

Argonne National Laboratory

9700 South Cass Avenue, Bldg. 208

Argonne, IL 60439

www.anl.gov 